\title{
A LA BÚSQUEDA DE UN SECTOR PESQUERO SOSTENIBLE
}

\author{
Gaspar Lloret Soriano \\ Estudiante de la Licenciatura de Geografía. Universidad de Alicante (España) \\ Correo electrónico: gls8@alu.ua.es
}

Recibido: 17 de mayo de 2011. Devuelto para revisión: 26 de mayo de 2011. Aceptado: 16 de junio de 2011

\section{RESUMEN}

El sector pesquero está atravesando graves problemas derivados de la sobreexplotación de los recursos animales, destrucción de los fondos marinos por los diversos tipos de pesca, la extracción de peces inmaduros, etc. Todos estos problemas tienen su origen en la década de los años 80 con la mecanización de las embarcaciones pesqueras, aumentando la potencia de las embarcaciones, los niveles de capturas y los modos de pesca.

Desde diversas instituciones en los tres ámbitos de actuación (internacional, nacional y local) se están haciendo grandes esfuerzos para intentar reducir estos impactos negativos, buscando un sector pesquero más sostenible, que pueda abastecer de alimentos a las sociedades y a la vez, reducir los impactos negativos del entorno. Estas instituciones están fomentando con grandes inversiones las actividades acuícolas, como solución a la crisis de la pesca, y que cada vez está adquiriendo un mayor peso en la producción de nuestra sociedad.

Palabras clave: Pesca, sostenibilidad, políticas pesqueras, acuicultura, Villajoyosa.

\begin{abstract}
The fishing sector is facing serious problems due to the excessive exploitation of animals, the destruction of the bottom of the sea because of the different types of fishing, the extraction of immature fishes, etc. We find the origin of all these problems in the 80's thanks to the mechanization of the fishing boats, which increased the power of the boats, the catch levels and the different ways of fishing.
\end{abstract}

From several institutions in the three fields of action (international, national and local) great efforts are being made in order to reduce these negative impacts, looking for a more sustainable fishing industry that can supply societies with food. At the same time, they will reduce the negative impacts of the environment. These institutions are promoting the aquaculture activities with great inversions as a solution to the fishing crisis and it is increasingly achieving a greater weight in the production of our society. Key words: Fishing, Sustainability, Fishing Policies, Aquaculture, Villajoyosa. 


\section{INTRODUCCIÓN}

Las actividades pesqueras han seguido en Europa una evolución similar en la agricultura, con una pérdida creciente de empleo y de contribución al Producto Interior Bruto de las diferentes economías. Aun así, pese a este declive tan sólo en el territorio de la Unión Europea encuentran ocupación en el sector más de 300.000 pescadores, a los cuales cabría sumar otros varios cientos de miles de obreros empleados en las industrias vinculadas con el sector pesquero, como conservas o los astilleros navales. Además, esta actividad adquiere una importancia estratégica en algunas áreas como las regiones atlánticas de la península ibérica, que concentran un tercio del empleo comunitario en el sector pesquero. Conviene también destacar, sin abandonar el ámbito de la Unión Europea, que los productos de la pesca constituyen la segunda partida más importante de las importaciones de alimentos, después de las frutas y hortalizas, de ahí que pueda considerarse un sector estratégico en la economía europea.

A escala planetaria, según estimaciones recientes de la FAO, se calcula que más de dos tercios de las reservas mundiales de peces se estaban pescando a un nivel de productividad máxima e incluso por encima de él, de forma que seis de las once regiones pesqueras más importantes del Atlántico y el Pacífico padecen unos graves problemas de sobreexplotación. La gestión responsable de las pesquerías del planeta requería una disminución del exceso de capacidad de la flota y una mayor cooperación internacional en el control de las capturas, especialmente para las zonas de alta mar que se extienden más allá de las 200 millas $(322 \mathrm{~km}$.) de las Zonas Económicas Exclusivas que reclaman las naciones costeras. Un referente obligado lo constituyen el Convenio de las Naciones Unidas sobre la Ley del Mar, negociado en 1982, el Acuerdo Internacional Vinculante sobre Gestión Conjunta de Bancos de Peces Migratorios (1995), y el Código de Conducta de Pesquerías Responsables de la FAO (1995) que, a grandes rasgos, recogen los principios del desarrollo sostenible aplicados a la explotación de los recursos pesqueros.

Este artículo está estructurado de tal modo que podamos abarcar todos los campos de acción de las instituciones pesqueras, pasando de las instituciones internacionales como es la Política Pesquera Común, y las nacionales, hasta el ámbito local, donde es donde repercuten estas actuaciones. El último tema lo he dedicado a la acuicultura como solución a los problemas que atañen a la pesca y que dichas instituciones intentan solucionar sin demasiada eficacia. En el ámbito local nos hemos centrado en el municipio de Villajoyosa, ya que se trata de una localidad que durante décadas se ha dedicado de forma directa a la actividad pesquera como tantos pueblos de nuestro entorno, donde son los lugares donde afecta de manera primordial los problemas o decisiones que se aprueban en las grandes instituciones europeas o nacionales.

\section{LA POLÍTICA PESQUERA COMÚN}

\section{Gestión de un recurso común}

En los países comunitarios, la explotación, gestión y regulación del sector remite necesariamente a la Política Pesquera Común (PPC). 
Las primeras medidas comunes en el sector pesquero se establecieron en 1970, cuando se acordó que los pescadores de la UE debían tener igualdad de acceso a las aguas de los Estados miembros. Aun así, se reservó una franja costera para que los pescadores locales que faenaban tradicionalmente cerca de sus puertos de origen pudieran seguir haciéndolo. También se adoptaron medidas para crear un mercado común de productos de la pesca y se estableció una política estructural para coordinar la modernización de los buques y de las instalaciones en tierra.

Todas estas medidas adquirieron un mayor declive en 1976, cuando los Estados miembros ampliaron sus derechos a los recursos marinos de 12 a 200 millas a partir de sus costas y decidieron que la Unión Europea era mejor interlocutor que cada uno de ellos para gestionar los caladeros de aguas bajo su jurisdicción y defender sus intereses en los foros internacionales. Tras años de arduas negociaciones, la PPC vio la luz en 1983. Los principales instrumentos de regulación, con unos mecanismos de control que pueden ser supervisados por inspectores de la Unión, residen en el establecimiento de unas tasas de explotación distribuidas por países denominadas Totales Admisibles de Capturas (TAC), calculadas anualmente por comités científicos para cada región de pesca. Por otro lado, desde 1995, también se aplica el llamado régimen de esfuerzo pesquero, que relaciona el volumen de capturas con la capacidad de pesca de la flota.

La adopción de medidas post productivistas para aliviar la situación se sobreexplotación de los calderos comunitarios y la necesidad de desarrollar estrategias competitivas en los mercados internacionales motivaron en 1994 la creación del Instrumento Financiero de Orientación de la Pesca (IFOP) para ofrecer un apoyo económico a las siguientes medidas:

a) Ajuste del esfuerzo pesquero, con desguaces incentivados en los barcos.

b) Renovación y modernización de la flota, siempre que no se aumente la capacidad extractiva.

c) Impulsar la pesca experimental.

d) Fomento de la acuicultura.

e) Mejora de las condiciones terrestres de la actividad pesquera, con ayudas a la mejora de redes de comercialización y divulgación publicitaria.

La adopción de este fondo, para el período1994-1999, podía complementarse con ayudas de otra procedencia, como las concebidas a través de la iniciativa comunitaria PESCA o las medidas socioeconómicas concebidas por FEDER o FSE a las regiones europeas dependientes de la pesca.

Veinte años después se reformó radicalmente. El objetivo de la reforma de 2002 era garantizar el desarrollo sostenible de la actividad pesquera desde los puntos de vista ecológico, económico y social. Las actividades más importantes de la Política Pesquera Común son las siguientes:

- Establecer normas para que la pesca en Europa sea sostenible y no perjudique al medio marino.

- Conferir a las autoridades nacionales instrumentos para hacer cumplir esas normas y sancionar a los infractores.

- Vigilar el tamaño de la flota pesquera europea e impedir que crezca.

- Proporcionar financiación y asistencia técnica para las iniciativas que contribuyan a la sostenibilidad del sector pesquero. 
- Negociar en nombre de los países de UE en los foros internacionales de pesca y con países de todo el mundo.

- Ayudar a los productores, transformadores y distribuidores a obtener un precio justo para su producción y garantizar la confianza de los consumidores en el pescado que comen.

- Apoyar el desarrollo de un sector acuícola dinámico en la UE (criaderos de peces, mariscos y algas).

- Financiar la investigación científica y la recopilación de datos para ofrecer una base sólida a la política y la toma de decisiones.

La Comisión ha iniciado una revisión de la Política Pesquera Común para hacerla más eficaz y garantizar la viabilidad económica de las flotas europeas, la conservación de las poblaciones de peces, la integración con la política marítima y el abastecimiento de alimentos de calidad para los consumidores.

La Política Pesquera Común se reformó en 2002 para garantizar la explotación sostenible de los recursos acuáticos vivos. Se introdujo entonces un criterio de precaución encaminado a proteger y conservar esos recursos y reducir al mínimo el efecto de la actividad pesquera en los ecosistemas marinos. La meta era contribuir a la eficacia de las actividades en una industria pesquera y acuícola económicamente viable y competitiva, ofrecer un nivel de vida equitativo a quienes dependen de la actividad pesquera y tomar en cuenta los intereses del consumidor.

La reforma de 2002 introdujo una estrategia de gestión pesquera más a largo plazo, mediante planes plurianuales de recuperación de las poblaciones que estuvieran por debajo de los límites biológicos de seguridad y planes plurianuales de gestión de las demás poblaciones. El objetivo era la aplicación progresiva de una gestión pesquera basada en el concepto de ecosistema.

En 2008 la Comisión inició una revisión de la Política Pesquera Común en la que analizará los aciertos y desaciertos de la política actual y estudiará las experiencias de otros sistemas de gestión pesquera al objeto de entresacar posibles directrices para el futuro.

El Fondo Europeo de Pesca (FEP) es el elemento financiero de la PPC, tiene una vigencia de siete años (2007-2013) y un presupuesto total aproximado de 3.800 millones de euros. Es el que sustituye al anterior Instrumento Financiero de Orientación de la Pesca (IFOP). Su objetivo es sostener los objetivos de la Política Pesquera Común (PPC) mediante lo siguiente:

- Apoyo de la explotación sostenible de los recursos pesqueros y de un equilibrio estable entre éstos y la capacidad de la flota pesquera comunitaria.

- Consolidación de la competitividad y la viabilidad de los agentes económicos del sector.

- Fomento de métodos de pesca y producción respetuosa del medio ambiente.

- Apoyo adecuado a los trabajadores del sector.

- Incentivo al desarrollo sostenible de los caladeros.

Un principio de alcance global dentro de la FEP es la necesidad de respetar la igualdad entre hombres y mujeres, y fomentar la perspectiva de género en todas las etapas de 
aplicación de los programas nacionales. El Fondo apoya el establecimiento de redes y la difusión de buenas prácticas entre organizaciones que promueven la igualdad de oportunidades. Las estrategias de desarrollo local candidatas a la financiación del Fondo, también tendrán que proporcionar soluciones a medida para mejorar las competencias profesionales, la capacidad de adaptación y el acceso al empleo, destinadas en particular a las mujeres.

\section{Medio ambiente y marino}

La PPC cuenta con diversas medidas para limitar las repercusiones medio ambientales de la pesca. Entre ellas cabe mencionar la protección de las especies no objetivo mamíferos marinos, aves y tortugas-, los juveniles y las poblaciones vulnerables (por ejemplo la estrategia para prevenir las capturas accesorias y eliminar los descartes), o la protección de los hábitats vulnerables (por ejemplo las medidas para eliminar las prácticas pesqueras destructivas).

En su visión de los mares y océanos, la UE tiene siempre presente la protección del medio marino. La Directiva sobre estrategia marina, adoptada en 2008, es esencial para la Política Marítima Integrada de la UE. Y por otra parte, en lo que respecta a la gestión pesquera, la Política Pesquera Común sigue ya un planteamiento centrado en los ecosistemas. Esto significa una reducción de cantidad de pesca para afectar menos al medio ambiente, proteger los hábitats y especies marinos vulnerables contra las prácticas pesqueras destructivas, ser consciente de las repercusiones de los factores ecológicos en las poblaciones de peces para no someterlas a una presión pesquera peligrosa.

Estos criterios no sólo se aplican a la pesca en aguas europeas sino que se extienden a una preocupación más general por la salud de los océanos mundiales. Son los que presiden nuestra actuación en los contextos de las organizaciones regionales de pesca, los acuerdos de asociación en el sector pesquero, las negociaciones en la ONU y la formulación de políticas.

Se produce la creación de la Red Marina Natura 2000, con la finalidad, al igual que ocurre en el medio terrestre, es garantizar el mantenimiento o, en su caso, el restablecimiento de un estado de conservación favorable, de los tipos de hábitats naturales y de los hábitats de las especies de que se trate en su área de distribución natural. Asimismo, se incluye dentro de esta red, las Zonas de Especial Protección para las Aves (ZEPA), para la conservación de las aves marinas y aves marinas migratorias.

Las líneas de actuación van ligadas al establecimiento de una red de espacios marinos protegidos bajo las herramientas de Natura 2000 persigue asegurar la supervivencia a largo plazo de las especies y los hábitats más amenazados de Europa, contribuyendo a detener la pérdida de biodiversidad y favoreciendo la conservación y el uso sostenible del medio marino. 


\section{Relaciones con los terceros países}

Con los acuerdos de la III Conferencia de Naciones Unidas sobre Derecho Marítimo, en 1977, se reconocieron los derechos de los países ribereños para establecer las Zonas Económicas Exclusivas. Este hecho motivó que la Comisión Europea asumiese las competencias necesarias para negociar los acuerdos de pesca con terceros países, lo que genera costes que absorben el $40 \%$ de la política pesquera comunitaria.

La UE mantiene bastantes acuerdos con terceros países que le permiten acceder a sus caladeros. Con la reforma de 2002, los acuerdos pasaron de ser concesiones de acceso con una contrapartida financiera a verdaderas asociaciones para el desarrollo de la pesca sostenible y responsable.

Estos acuerdos internacionales desempeñan una importante labor en diversas organizaciones regionales de pesca que gestionan los recursos pesqueros en alta mar y luchan activamente contra la pesca ilegal y las prácticas pesqueras destructivas. En la actualidad, son 26 acuerdos suscritos en la UE y los países africanos, del océano Índico, del Atlántico norte y con los países iberoamericanos. Pese a ello, no faltan ejemplos de conflictos internacionales por el aprovechamiento de los caladeros internacionales. Como fue el caso del secuestro de la embarcación del Alakrana por piratas a 413 millas de las costas del sur de Somalia el 3 de octubre de 2009, cuando faenaban lejos de la zona protegida por la Operación Atlanta, pero dentro de la zona de seguridad en aguas internacionales. En su auxilio acudieron fragatas y tropas españolas. El 17 de noviembre del mismo año, tras 47 días de secuestro, el Alakrana fue liberado tras el pago de un rescate de unos 4 millones de dólares. A consecuencia del secuestro, la ley española fue modificada el 2 de noviembre de 2009 para permitir a los vigilantes de seguridad emplear armamento en los buques con bandera española, siempre que éste sea adquirido a fabricantes o distribuidores asentados en España. En cambio, en las embarcaciones de otras banderas sí que está permitida la presencia a bordo de militares y la tenencia de armamento superior al reglamentado para barcos españoles.

Más de la cuarta parte del pescado capturado por los pesqueros europeos procede realmente de aguas no pertenecientes a la UE. En torno al 8\% de las capturas de la UE (2004-2006) corresponde a acuerdos de pesca con terceros países, y un 20\% se pesca en alta mar, principalmente en zonas custodiadas por las llamadas organizaciones regionales de pesca.

La Unión Europea, potencia pesquera de primer orden y el mayor mercado mundial de productos de la pesca, ejerce un papel importante en el fomento de la gobernanza en varias organizaciones internacionales. Ello implica elaborar y aplicar una política de gestión pesquera $\mathrm{y}$, más generalmente, el Derecho del Mar. La UE colabora estrechamente con sus socios de todo el mundo a través de las Naciones Unidas concretamente la Organización de las Naciones Unidas para la Agricultura y la Alimentación (FAO) - y otras entidades como la Organización de Cooperación y Desarrollo Económicos (OCDE). 


\section{Una importante actividad económica}

La pesca y la acuicultura constituyen importantes actividades económicas de la Unión Europea. Su contribución al producto nacional bruto de los Estados miembros se cifra, por lo general, en menos del uno por ciento, pero en cambio son una fuente de empleo esencial en regiones en las que existen pocas alternativas. Además, el sector abastece de productos de la pesca el mercado de la UE, uno de los mayores del mundo.

Con una producción de casi 7 millones de toneladas de pescado en 2005, procedentes tanto de la pesca como de la acuicultura, la Unión Europea es la segunda potencia pesquera mundial después de China. Aun así, en 2006, pese a haber exportado 2 millones de toneladas de productos de la pesca, tuvo que importar 6 millones para satisfacer sus necesidades. Este desequilibrio entre importación y exportación provocó ese año un déficit de más de 13.000 millones de euros.

En el cuadro 1 de la balanza comercial del sector pesquero europeo en 2008 (en euros) observamos como países como Italia, Francia, España, Suecia, Alemania y Reino Unido tienen una balanza comercial negativa, que peses a ser uno de los principales países exportadores de productos de pesca y acuicultura, son los principales países importadores. Por el contrario, observamos otros países como Países Bajos, Irlanda, Dinamarca y Grecia tienen una balanza comercial positiva debido a que exportan más productos de los que importan.

La Unión Europea es uno de los tres principales importadores de productos de pesca y acuicultura, junto con Japón y Estados Unidos. Noruega, China e Islandia son los principales proveedores de la UE. Asimismo, revisten una gran importancia los intercambios en el interior de la UE, considerando todos los intercambios, tanto internos de la UE como con terceros países, España, Francia e Italia son los principales miembros importadores. Dinamarca y Países Bajos son los Estados miembros que más exportan, delante de España.

Cuadro 1. Balance comercial del sector pesquero en Europa, 2008 (en euros).

\begin{tabular}{|l|l|l|l|}
\hline Países & Exportación & Importación & Balance \\
\hline España & 2.337 .415 & 4.823 .554 & -2.486 .139 \\
\hline Francia & 1.337 .415 & 3.943 .154 & -2.605 .739 \\
\hline Alemania & 1.566 .120 & 3.081 .955 & -1.515 .835 \\
\hline Italia & 526.556 & 3.619 .054 & -3.092 .498 \\
\hline Suecia & 1.273 .518 & 1.846 .382 & -1.572 .864 \\
\hline Países Bajos & 2.338 .387 & 1.957 .928 & 380.459 \\
\hline Irlanda & 332.335 & 162.488 & 169.847 \\
\hline Dinamarca & 2.787 .494 & 1.876 .573 & 910.921 \\
\hline Grecia & 441.797 & 427.062 & 14.735 \\
\hline Reino Unido & 1.258 .970 & 2.731 .827 & -1.472 .857 \\
\hline
\end{tabular}

Fuente: Eurostat. Elaboración propia. 


\section{La flota y el empleo pesquero de la Unión Europea}

La flota pesquera de la UE cuenta con más de 80.000 buques, cuyas dimensiones y capacidad pesquera o capacidad potencial de capturas varían considerablemente. En los últimos años se ha reducido la capacidad de flota, ya que era excesiva para el pescado disponible y poco rentable, y era necesario para garantizar la explotación sostenible de los recursos. La Unión Europea ha facilitado la transición hacia un mayor equilibrio entre la flota y las poblaciones de peces, pero hacen falta más medidas. A tal efecto, la gestión de la capacidad de la flota es un instrumento esencial. Con arreglo al Derecho de la Unión Europea, la capacidad total de la flota pesquera no puede aumentar y, si se destinan fondos públicos al desguace de una embarcación de pesca, no se podrá sustituir la capacidad correspondiente, es decir, la reducción de la capacidad de la flota con financiación pública debe ser permanente. Por otra parte, la flota se seguirá modernizando para mejorar la seguridad de los buques, las condiciones laborales, la calidad de los productos y la selectividad de la pesca.

A lo largo de los últimos diecisiete años, la capacidad de la flota pesquera de la Unión Europea ha disminuido a un ritmo anual casi constante, algo por debajo del $2 \%$ tanto en términos de arqueo como de potencia. A pesar de las ampliaciones de la UE en 2004 y 2007, en septiembre de 2009 el número de embarcaciones era de 84 909, es decir 21000 menos que en 1995.

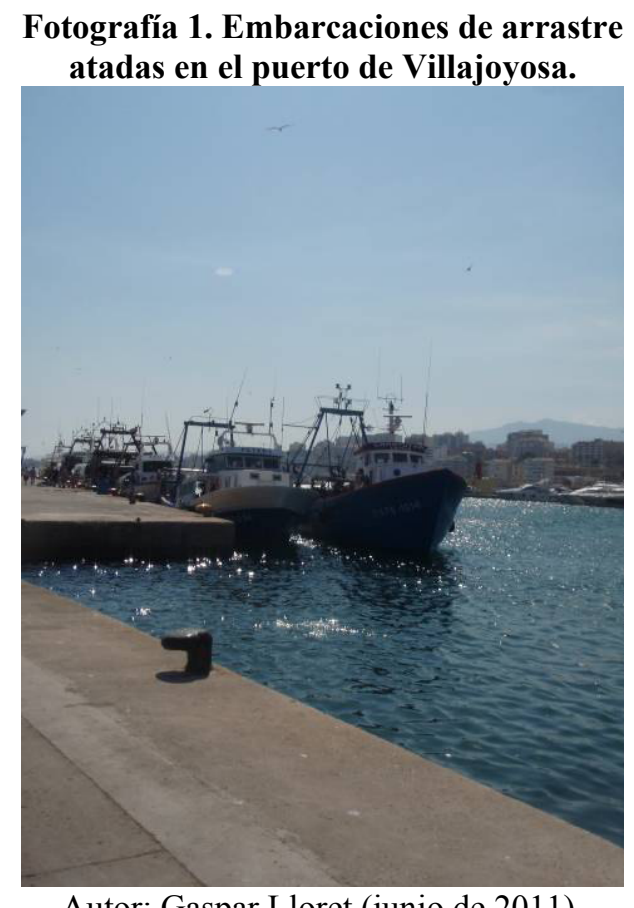

Autor: Gaspar Lloret (junio de 2011).

El empleo del sector primario en la pesca marítima, medida en equivalente a tiempo total, tiene una fuerte tendencia a concentrarse en unos países como observamos en la gráfica posterior. España representa una cuarta parte del empleo de la UE en el sector pesquero, y los países que la persiguen (Italia, Grecia, Portugal y Francia) junto con España suponen más del $75 \%$ del empleo en el sector. Se trata de unos datos muy llamativos ya que podemos observar como en tan solo cinco países se concentra la mayor parte de la población activa en el sector de la pesca. 
Con la reducción de la capacidad de flota de los últimos años se ha ocasionado una serie problemas. Las medidas de la Unión Europea para reducir el número de embarcaciones, como son las ayudas económicas para el desguace de las embarcaciones han supuesto una reducción del empleo de este sector. Estas ayudas económicas van destinadas a los dueños de las embarcaciones y no a los trabajadores, que ocasiona una disminución de la población activa del sector pesquero, y problemas económicos a muchas familias que eran totalmente dependientes de los ingresos económicos de este sector.

\section{La pesca sostenible}

El sector pesquero de la UE se enfrenta a problemas que ya han experimentado la mayoría de las industrias pesqueras del mundo. La sobreexplotación pesquera, que reduce las poblaciones y, con ellas, los desembarques y los ingresos, constituye la principal amenaza para el futuro de los caladeros y de la propia industria pesquera.

La creciente competencia resultante de la globalización del mercado es un reto más. La industria pesquera podrá competir si es capaz de adaptarse a las limitaciones impuestas por la disponibilidad de los recursos y la demanda del mercado. La Unión Europea ha facilitado ayuda financiera al sector durante su inevitable proceso de reestructuración. La ayuda se ajusta a los objetivos de la Política de Cohesión económica y social, dirigida al desarrollo de las regiones menos favorecidas de la UE.

Figura 1. Empleo en el sector de la pesca (2007).

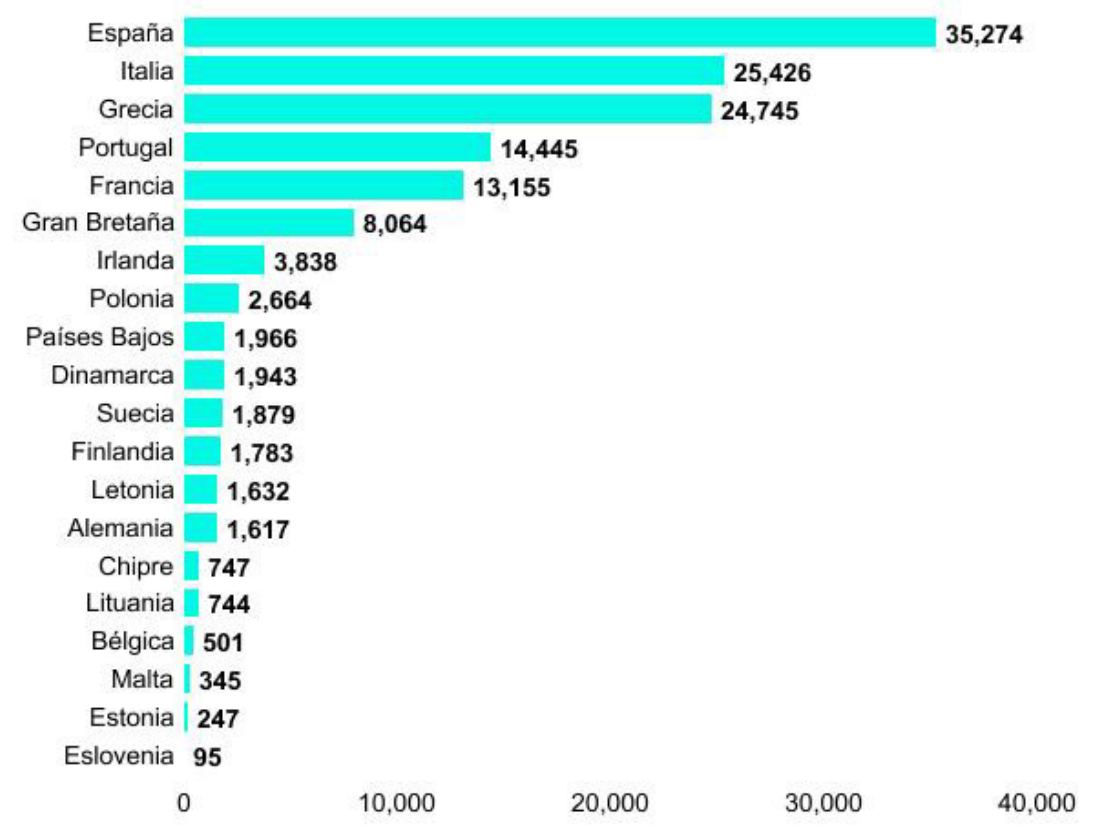

Total EU-27: 141.110

Fuente: Comisión Europea. The 2009 Annual Economic Report on the European Fishing Fleet, Luxemburgo. Oficina de Publicaciones Oficiales de las Comunidades Europeas, 2009. (Informe EUR 24069 EN). Elaboración propia.

La pesca ilegal, no declarada y no reglamentada (pesca INDNR) agota las poblaciones de peces, destruye los hábitats marinos, distorsiona la competencia, supone una 
desventaja injusta para los pescadores legales, y efectos a las comunidades costeras, especialmente en los países en desarrollo. La UE trabaja activamente para cerrar los resquicios que permiten a los ilegales obtener beneficio de sus actividades:

- Según las normas adoptadas recientemente, sólo los productos de la pesca marina certificados legales por el Estado de abanderamiento correspondiente o el Estado exportador pueden importarse en la UE o exportarse de ella.

- Se ha compilado una lista negra europea de buques de pesca INDNR y Estados que hacen la vista gorda ante las actividades pesqueras ilegales.

- A los pescadores de la UE que pesquen ilegalmente en cualquier lugar del mundo y bajo cualquier pabellón se les aplican sanciones importantes, proporcionales al valor económico de su captura, que los privan de cualquier beneficio.

- El nuevo Reglamento de la UE para prevenir, desalentar y eliminar la pesca ilegal, no declarada y no reglamentada entró en vigor 1 de enero de 2010.

Las poblaciones de peces tienen una productividad natural alta, pero no ilimitada. Si se capturan más peces que el excedente natural de las poblaciones, se reduce el potencial de producción para el futuro. Por ello va en interés de todos tener una normativa que garantice que las poblaciones se repartan equitativamente y no se agoten a corto ni a largo plazo. Hay tres tipos de normas de pesca:

- Limitación del esfuerzo pesquero: se restringe el tamaño de la flota en el mar y el tiempo que puede estar faenando.

- Límites de capturas: se restringe la cantidad de pescado que puede capturarse en el mar.

- Medidas técnicas: se regula dónde y cómo pueden faenar los pescadores. Pueden utilizarse, por ejemplo, para proteger peces jóvenes (juveniles), fomentar el uso de artes de pesca más selectivos o prevenir perjuicios graves al medio marino.

La política pesquera recurre a los tres tipos por separado o en combinación. Los planes plurianuales, establecidos para gestionar poblaciones de peces concretas, suelen combinar los tres.

El Fondo Europeo de Pesca (FEP) tiene un presupuesto de 4.300 millones de euros para el periodo 2007-2013. Pueden optar a la financiación todos los sectores de la industria pesquera: pesca marina e interior, acuicultura (peces, moluscos y plantas acuáticas), transformación y comercialización. Se presta especial atención a las comunidades pesqueras más afectadas por los cambios recientes.

Se financian proyectos basados en los planes estratégicos y programas operativos elaborados por las autoridades nacionales. La financiación tiene cinco ámbitos (ejes) prioritarios:

- Ajuste de la flota (por ejemplo, desguace de buques pesqueros).

- Acuicultura, transformación, comercialización y pesca continental (por ejemplo, métodos de producción más ecológicos).

- Medidas de interés común (por ejemplo, trazabilidad y etiquetado de los productos). 
- Desarrollo sostenible de las zonas dependientes de la pesca (por ejemplo, diversificación de la economía local).

- Asistencia técnica para financiar la administración del Fondo.

En Europa, el potencial de producción de peces y mariscos mediante técnicas de acuicultura superaba ya a mediados de los años noventa un volumen de 1.300 .000 t., lo que suponía alrededor del $7 \%$ de las capturas totales. En la actualidad representa casi el $20 \%$ de la producción de pescado y da empleo directo a unas 65.000 personas. Aun así hay países europeos como Noruega, con más de 700 instalaciones acuícolas destinadas al a cría de trucha y sobre todo del salmón, con una producción de unas 800.000 toneladas; a mayor distancia quedarían Francia (255.200 t.), España (173.500 t.) o Italia (154.400 t.), donde la acuicultura también se está convirtiendo en una alternativa a la sobreexplotación de los recursos pesqueros convencionales. La acuicultura de la Unión Europea tiene fama por las estrictas normas que aplica a sus productos y métodos de producción.

El progreso en calidad no se refleja sin embargo en un aumento de la producción acuícola, que desde 2000 se mantiene más o menos constante, mientras que en el resto del mundo ha crecido un 33\%. En un análisis más detallado se observa que los distintos sectores de la acuicultura avanzan en direcciones casi opuestas. La producción europea de peces marinos sigue creciendo, pero la de moluscos y de peces de agua dulce presenta una disminución constante durante los últimos años.

El desarrollo de una acuicultura más competitiva y ecológica es un objetivo primordial de la financiación europea, tanto a través del Fondo Europeo de Pesca (FEP) como de los programas de investigación de la UE. En 2009, la Comisión propuso una estrategia para el futuro de la acuicultura europea.

Destacan numerosas iniciativas de cultivos marinos que se están desarrollando en el Mediterráneo, aprovechando en gran medida de cultivos marinos la fuerte demanda que genera la actividad turística de las ciudades costeras. Así, destacan los cultivos acuícolas para la eclosión de moluscos en Sète, en el Languedoc-Rousillon; la eclosión y engorde de lubinas y doradas en Cerdeña, o de anguilas, doradas, sabalote o lubinas en diversos puntos del litoral mediterráneo español, desde el Delta del Ebro a las salinas del Cabo de Gata.

\section{El mercado de productos de la pesca}

La industria pesquera no se limita a la pesca, sino que abarca mucho más. Toda una cadena de operaciones va desde las redes del pescador hasta la mesa del consumidor. La Política Pesquera Común (PPC) está presente en cada etapa.

El régimen de organización de mercados de la UE - conocido como organización común de mercados - sirve para compensar las variaciones en el suministro y los precios en beneficio de pescadores, transformadores y consumidores. Su meta es equilibrar las necesidades del mercado y los intereses de los pescadores en la Unión Europea y garantizar el cumplimiento de las normas de competencia legal. 
Dentro del régimen de mercado de la UE, en muchas regiones los agentes del sector pesquero se organizan en organizaciones de productores que planifican la producción y elaboran estrategias de mercado. La Comisión colabora en el etiquetado para dar una información correcta al consumidor y garantizar el seguimiento completo de los productos de la pesca.

Facilitar el comercio exterior es una dimensión esencial de las relaciones de la industria pesquera de la UE con el resto del mundo, máxime cuando la UE es el mayor mercado mundial de productos de la pesca, donde todos los productos de la pesca vendidos en la UE tienen que cumplir normas rigurosas de higiene alimentaria.

Por especies, en crustáceos, moluscos y cefalópodos, los principales países productores europeos son, según datos de 1995, Francia (297.000 t), Italia (288.000 t), España (274.936 t) y Rusia (145.000 t). En cambio, en peces marinos ese orden se invierte con Rusia (3.787.417 t) en primer lugar, seguida de Noruega (2.474.579 t), Islandia $(1.515 .701 \mathrm{t})$, Dinamarca $(1.450 .863 \mathrm{t})$ y España $(1.016 .746 \mathrm{t})$. Tampoco son desdeñables las capturas de especies de agua dulce, que suponen para Europa un volumen cercano al millón de toneladas métricas, destacando por encima de otros países la contribución de Rusia (375.200 t) y Ucrania (105.000t).

\section{El régimen de control de la pesca de la Unión Europea}

Para que se cumplan las normas de la Política Pesquera Común existe un régimen de control con los instrumentos necesarios. Estas normas tienen la finalidad de: vigilar que sólo se capturen las cantidades permitidas, recopilar los datos necesarios para gestionar las posibilidades de pesca, delimitar las funciones de los Estados miembros de la UE y la Comisión, asegurarse de que las normas se apliquen a todos los pescadores por igual, con sanciones armonizadas en toda la UE, garantizar que los productos de la pesca puedan rastrearse y comprobarse a través de la cadena de suministro, de la red a la mesa.

El régimen se establece en el Reglamento de control, que entró en vigor el 1 de enero de 2010 y que moderniza a fondo el control de la pesca de la UE y, en concreto, lo adecua a las estrictas medidas adoptadas en 2008 contra la pesca ilegal en alta mar.

La Comisión cuenta con 25 inspectores empleados a tiempo completo que realizan entre todos unas 130 inspecciones al año. Su función consiste en comprobar los sistemas de inspección nacionales, en concreto de sus defectos y sus lagunas. Su trabajo exige el mismo nivel de atención y precisión que el de los inspectores nacionales, sobre todo en los casos en que se detectan fallos importantes. Los resultados que se obtienen son cruciales a la hora de dota a la Comisión de una base sólida de actuación contra los Estados miembros, cuando procede, y deben ser capaces de soportar los procedimientos jurídicos más estrictos.

Uno de los caso sucedió en el año 2007, cuando la Comisión sospechó que existían deficiencias importantes en las declaraciones de los desembarques de bacalao del mar Báltico, fueron los inspectores de la Comisión los que visitaron los puertos de la costa y comprobaron los resultados de la declaración nacional y los sistemas de inspección. Y fueron sus análisis y sus estimaciones del peso real de los desembarques no 
inspeccionados los que conformaron la base de la decisión de la Comisión de clausurar la pesquería y de las consiguientes medidas de devolución de la cuota de sobrepesca por parte de un Estado miembro.

\section{Las cuencas marinas}

Europa está rodeada de océanos y mares. La UE cuenta aproximadamente con 70.000 $\mathrm{Km}$. de costa y casi la mitad de sus ciudadanos vive a menos de $50 \mathrm{Km}$. del mar. Aproximadamente un 40\% del PIB de la UE se genera en las regiones marítimas y nada menos que un $90 \%$ del comercio exterior se lleva a cabo por mar.

Para destacar la importancia de los océanos y mares de Europa, la Comisión Europea ha elaborado un Atlas Europeo del Mar destinado a todos los interesados en el mundo marino y en nuestro patrimonio marítimo común.

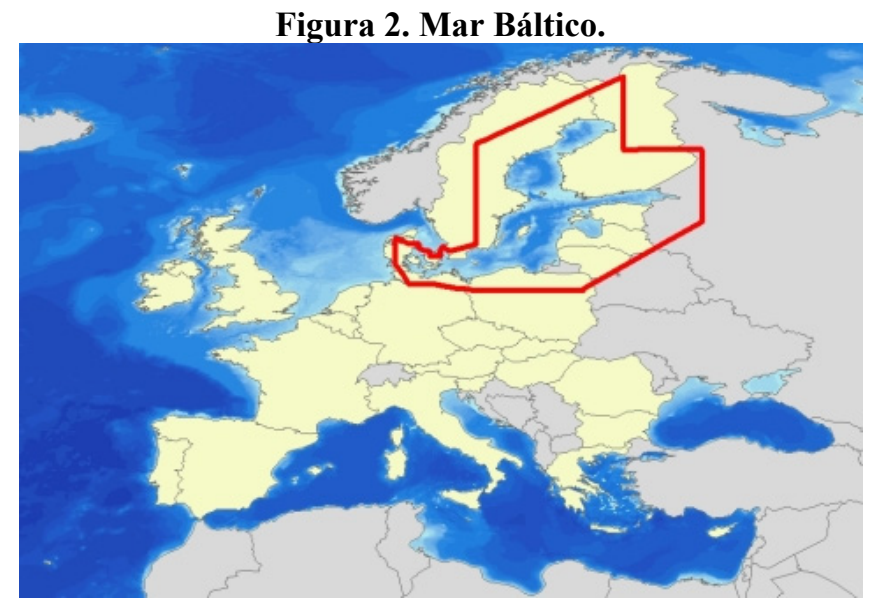

Fuente: Imagen extraída de la página web de la Comisión Europea, Atlas Europeo del mar.

El Mar Báltico está casi completamente cerrado y es poco profundo salvo en algunas zonas. Sus aguas se renuevan muy lentamente. Sus extremos Norte y Nordeste están helados la mayor parte del año, y su salinidad es muy baja.

Figura 3. Mar del Norte.

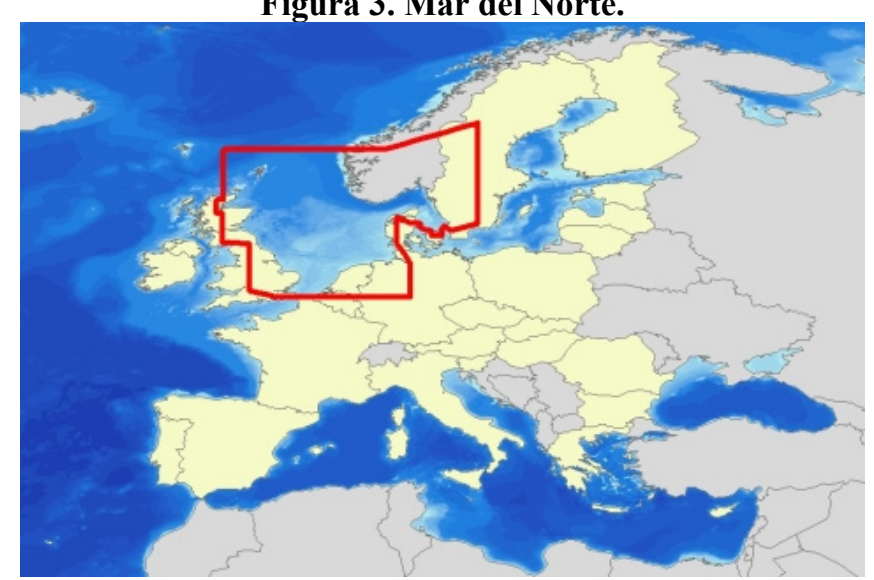

Fuente: Imagen extraída de la página web de la Comisión Europea, Atlas Europeo del mar. 
El Mar del Norte es un mar semicerrado y poco profundo, excepto en su zona septentrional. Su ecosistema es cada vez más frágil debido a la intensa actividad humana, tanto en la costa como en alta mar. Esta riqueza pesquera se produce al mezclarse la corriente noratlántica europea con la que procede del círculo polar ártico.

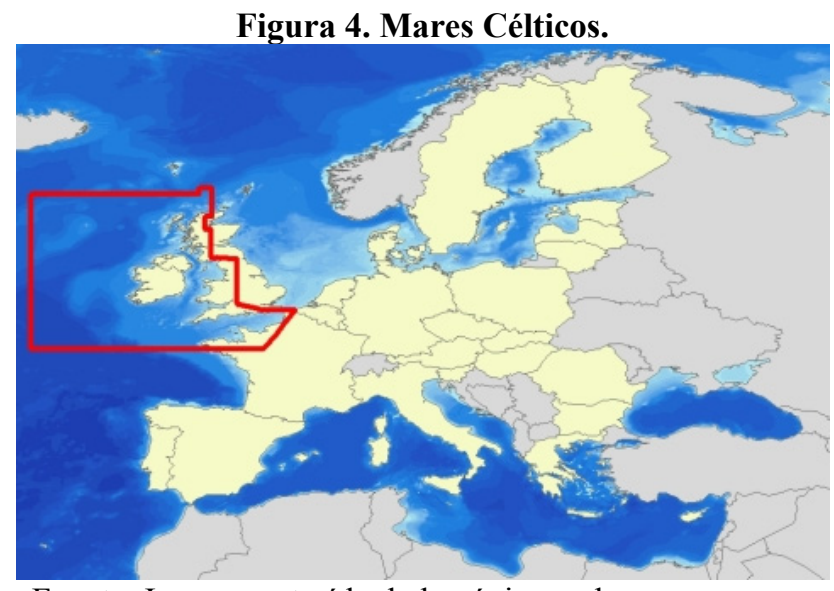

Fuente: Imagen extraída de la página web de la Comisión Europea, Atlas Europeo del mar.

En esta denominación se incluyen el Canal de la Mancha, el Mar de Irlanda, el Mar Céltico propiamente dicho y las aguas al oeste de las Islas Británicas.

Por esta ventosa extensión marina ha circulado siempre una intensa navegación y la mayoría de los mercantes que hacen la ruta Este-Oeste.

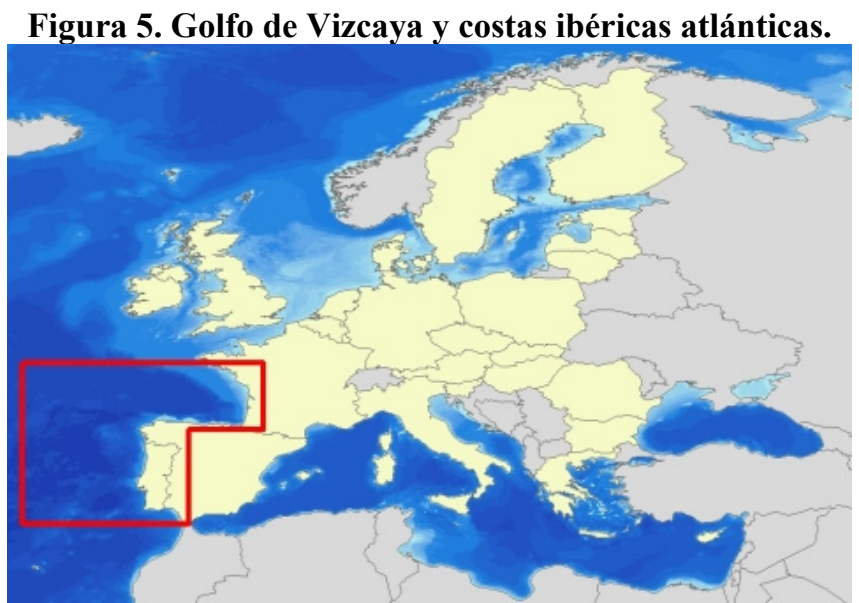

Fuente: Imagen extraída de la página web de la Comisión Europea, Atlas Europeo del mar.

La zona del Golfo de Vizcaya y las costas ibéricas atlánticas se extiende desde el sur de Bretaña hasta el Estrecho de Gibraltar. Forma parte de la ruta que enlaza los mares del Norte con el Mediterráneo y África. La región es la cuna del poder marítimo europeo. En los siglos XV y XVI, los viajes de los descubridores partían de las costas españolas y portuguesas.

Actualmente, los puertos de la zona ya no figuran entre los más importantes, y en ellos la mayoría de las operaciones corresponden a importaciones de crudo. Sigue habiendo sin embargo una activa industria pesquera, de ámbito local en el Cantábrico y Golfo de 
Vizcaya, por ejemplo, y con flotas de pesca de altura en Bretaña y Galicia. En la región se está desarrollando la acuicultura y el turismo de playa está bien desarrollado.

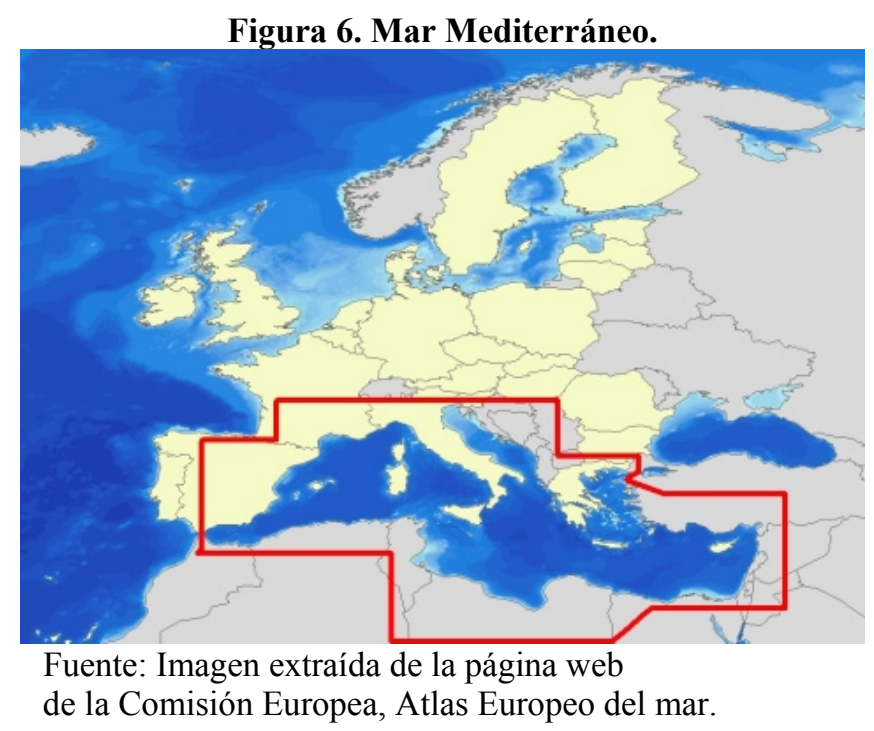

El Mediterráneo, mar casi enteramente cerrado, es sin embargo bastante profundo (una media de $1.500 \mathrm{~m}$ ). Sus mareas son débiles, con una amplitud por debajo de $50 \mathrm{~cm}$ en su mayoría. El clima es cálido y seco. El agua, cálida también, es muy salina. Aunque pobre en nutrientes, posee una rica biodiversidad. Cuna de las antiguas culturas de Egipto, Creta, Micenas, Grecia y Roma, el Mediterráneo es el origen de la civilización europea.

La UE tiene aproximadamente $4.000 \mathrm{~km}$ de costa mediterránea. El mar separa Europa de África, con una distancia de apenas $30 \mathrm{~km}$ en el Estrecho de Gibraltar pero de 1.600 $\mathrm{Km}$. en algunos puntos.

El Mediterráneo, principal destino turístico del mundo, es también una vía de navegación de primer orden, y casi la tercera parte de todo el tráfico mercante internacional pasa por él. La acuicultura está bien asentada, y la industria pesquera (principalmente de pequeña escala) es una importante fuente de empleo.

Aunque casi cerrado, el Mar Negro es profundo. Sus aguas, con escasa presencia de oxígeno, son extremadamente vulnerables.

Excepto la Guayana Francesa, las regiones ultraperiféricas son islas o archipiélagos oceánicos. Aunque pequeñas, constituyen una amplia extensión de la UE en los océanos tropicales y subtropicales. Canarias, Madeira, Azores, Guayana Francesa, Guadalupe y Martinica están situadas en el Atlántico central, y la Reunión en el Índico.

Tienen pocos puertos importantes, con la excepción de Las Palmas de Gran Canaria. Pero mantienen diversas actividades comerciales, como la pesca y la navegación, y están muy bien situadas para ubicar la investigación marina y otras actividades innovadoras. 
Figura 7. Mar Negro.

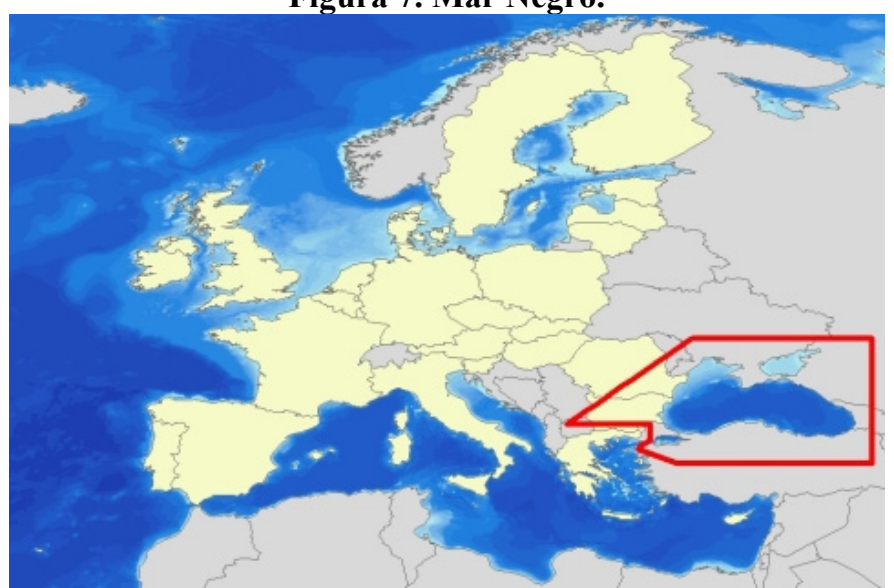

Fuente: Imagen extraída de la página web de la Comisión Europea, Atlas Europeo del mar.

Figura 8. Regiones Ultraperiféricas.

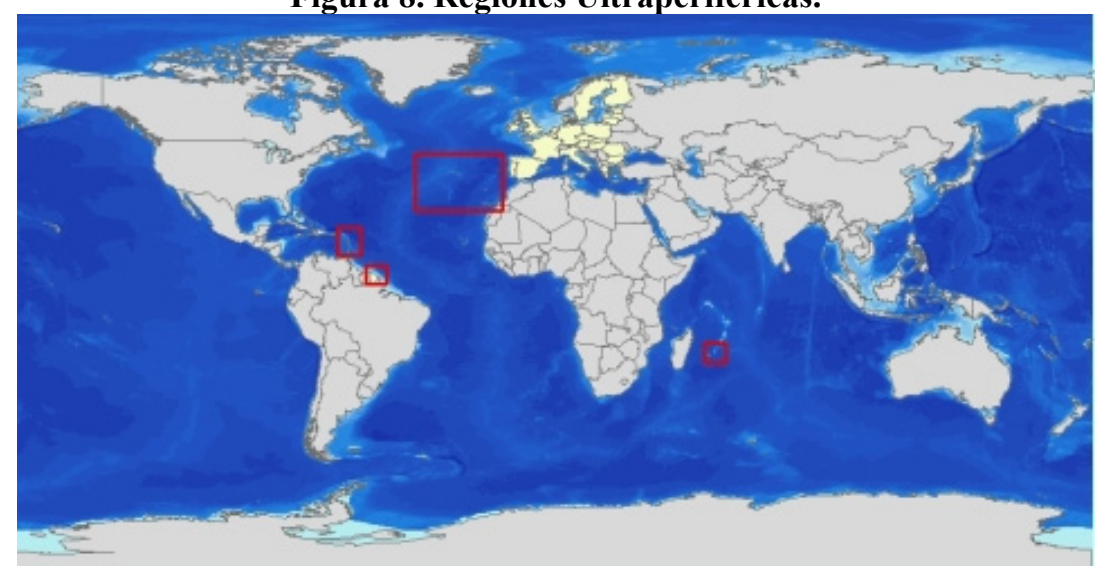

Fuente: Imagen extraída de la página web de la Comisión Europea, Atlas Europeo del mar. 


\section{Figura 9. Océano Ártico.}

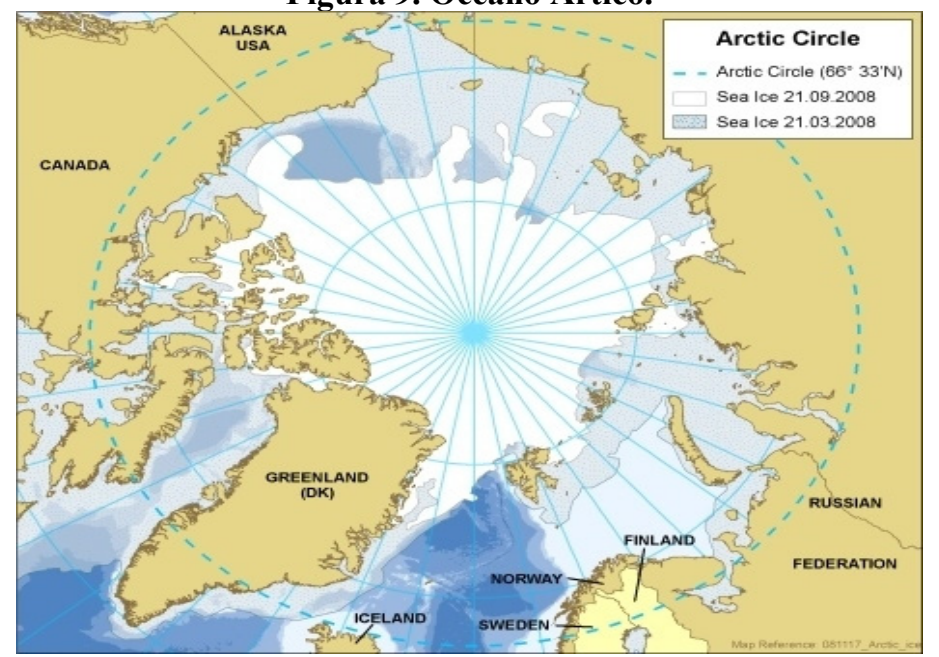

Fuente: Imagen extraída de la página web de la Comisión Europea, Atlas Europeo del mar.

El Océano Ártico es una extensa zona marina cuyo centro es el Polo Norte. Con sus mares adyacentes, baña las costas septentrionales de Europa, Asia y América.

Por diversas razones, la totalidad de los países europeos padecen problemas de sobreexplotación de sus recursos pesqueros, tanto de los propios como de los explotados en regiones de pesca foráneas. Un carácter casi irreversible revisten los daños causados a los caladeros explotados por Rusia en el mar de Aral, mar de Azov, mar Caspio o lago Baikal, con reducciones de capturas que pueden suponer en algunos casos más del $90 \%$ en especies tan apreciadas como el esturión. Aun así, pese a la crisis que padece el sector pesquero ruso por falta de capitalización, este país cuenta con unos importantes caladeros en el Pacífico y mar de Barents, que le otorgan primacía en Europa por volúmenes de capturas, destinándose en parte a importantes complejos industriales de transformación.

En situación algo más favorable se encuentran los caladeros tradicionales de la Unión Europea, sobre todo las regiones del Atlántico noroeste, de donde se obtiene el $71 \%$ de las capturas comunitarias, con más de 5 millones de toneladas en 1995. En cambio, se han producido unas reducciones importantes, a veces alcanzando el 80\%, en otra regiones, como ha sucedido en el período 1985-1995 con el Atlántico sudeste, Atlántico centro-oriental y Atlántico noroeste, mientras que en el Mediterráneo, donde no se han establecido Zonas Económicas Exclusivas, el grado de explotación de mediados de los noventa era muy superior al de mediados de los ochenta.

Para hacer frente a esta sobreexplotación, en el caladero mediterráneo se aplica desde 1995 un Régimen Común de Conservación de la Pesca, basado en el establecimiento de paros biológicos.

La evolución de las actividades pesqueras ha ido vinculada a los avances técnicos experimentados en los sistemas y artes de pesca, a la dimensión y potencia de la flota pesquera y a la transformación industrial de los recursos obtenidos. Dinamarca es el principal país pesquero de la Unión Europea con 1,5 millones de toneladas, pero destina sus capturas a uso industrial, sobre todo en la fabricación de harinas y aceites; en 
cambio, las capturas de la flota española, las segundas en importancia de la UE-15, se dirigen a satisfacer la demanda para la alimentación humana.

Por su parte, la flota pesquera europea duplica con creces en la actualidad la potencia de hace tres décadas, de forma que tan sólo en la Europa comunitaria son más de 100.000 los buques que practican esta actividad, con una capacidad superior a 2 millones de toneladas, resaltando la contribución de España (615.000 toneladas y unos 20.500 buques), Italia (260.000 toneladas y 16.000 buques), Reino Unido (250.000 toneladas y 10.900) y Francia (197.000 toneladas y 7.700 embarcaciones). No obstante, cabe advertir que el sistema de <<quota hopping $>>$ disfraza a veces el origen real de las tripulaciones y el destino de la pesca capturada, como sucede en Reino Unido, donde más de 150 buques con pabellón de ese país faenan con cargo a sus cuotas nacionales pero cuentan con propiedad, tripulación y descarga de capturas en puertos de otros países comunitarios.

\section{LA PESCA EN ESPAÑ}

Las reservas marinas constituyen una medida específica que contribuye a lograr una explotación sostenida de los recursos de interés pesquero, estableciendo medidas de protección específicas en áreas delimitadas de los caladeros tradicionales. Estas áreas, en cuya selección se tiene en cuenta su estado de conservación, deberán reunir determinadas características que permitan la mejora de las condiciones de reproducción de las especies de interés pesquero y la supervivencia de sus formas juveniles. El efecto de una reserva marina se manifiesta por una recuperación significativa de los caladeros en los que está inserta por efecto de la dispersión de las especies cuya reproducción se ha protegido en la misma.

\section{El Fondo de Regulación y Organización de Mercado de los Productos de la Pesca y Cultivos Marinos (FROM)}

El Fondo de Regulación y Organización del Mercado de los Productos de la Pesca y Cultivos Marinos (FROM), es un Organismo Autónomo, creado por el Ministerio de Medio Ambiente y Medio Rural y Marino. Este Organismo centra sus actividades en el diseño y desarrollo de acciones encaminadas a promocionar el consumo de productos pesqueros, orientar el mercado de estos productos en cuanto a cantidades, precios y calidades, y asistir en sus necesidades técnicas o financieras a asociaciones, cooperativas y empresas del sector.

Para desarrollar sus funciones, el FROM cuenta con una Secretaría General que ejerce, además, las labores operativas del mismo en materia de recursos humanos, gestión económica, financiera, presupuestaria y de régimen interior. El FROM tiene entre sus objetivos de trabajo el asegurar la calidad de los servicios que presta.

Este cometido nos obliga a mantener un compromiso de mejora continua de los mismos, para satisfacer de forma eficaz las necesidades y expectativas de los ciudadanos.

Nuestra Carta de Servicios recoge este compromiso asumido por el FROM, a la vez que describe los servicios prestados y facilita la información que consideramos de interés para todos los usuarios. 
A través de ella, queremos afirmar nuestra vocación de servicio al ciudadano, y resaltar la enorme importancia que tiene la participación de todos (funcionarios y usuarios) en la mejora de la calidad de nuestras actuaciones.

\section{Medidas contra la protección de los hábitats marinos: los arrecifes artificiales}

La política pesquera española contempla los arrecifes artificiales como una medida de protección directa de los hábitats de interés pesquero y, por tanto, de regeneración de los recursos.

Los inicios de esta línea datan de principios de los años 80 , y se ven fortalecidos por la adhesión de España a la CEE. Durante la década de los 90 y a la vista de su eficacia, se consolidan como medida de gestión pesquera. Se definen jurídicamente como conjunto de elementos, constituidos por diversos materiales inertes y con diversas formas (...), que se distribuyen sobre una superficie delimitada del lecho marino. Desde el punto de vista pesquero, un arrecife artificial es un instrumento de ordenación que permite la protección de los recursos y de los ecosistemas de interés pesquero, y que localmente puede lograr el desarrollo de estos mismos recursos reduciendo la mortalidad de las fases juveniles antes de su reproducción, facilitando fuentes de alimentación para determinadas especies y haciendo posible la supervivencia de adultos reproductores en zonas nuevas, permitiendo además la mejora en la gestión de los usos de estos recursos.

\section{La pesca marítima de recreo}

Se entiende por Pesca Marítima de Recreo, la que se realiza por entretenimiento, deporte o afición y sin ánimo de lucro, y en la cual sus capturas no podrán ser objeto de venta ni transacción. Se pueden distinguir las siguientes modalidades:

- Desde tierra. Es la que se practica a pie desde la costa.

- Desde embarcación. Es la que se ejerce desde embarcaciones aptas para esta actividad e inscritas en la lista correspondiente del Registro Oficial de Buques.

- Submarina. Que es la que se practica buceando a pulmón libre, sin utilizar ningún tipo de elemento que permita la respiración en inmersión, ni de medios mecánicos de propulsión.

La práctica de la actividad de la pesca marítima de recreo se desarrolla con frecuencia en el mismo ámbito espacial que la actividad pesquera profesional, afectando por tanto a las mismas especies comerciales a las que ésta va dirigida. Esta actividad ha experimentado un gran auge en los últimos años, y va en aumento, en consonancia con las nuevas preferencias en las prácticas de ocio de nuestra sociedad, por lo que resulta de gran importancia el mejorar la difusión, conocimientos e información a los interesados y a la sociedad en general, sobre su regulación normativa y principales aspectos de relevancia, con el fin de lograr un desarrollo adecuado y sostenible de esta actividad, compatibilizando los beneficios tanto económicos como de ocio con la necesidad de preservar los recursos pesqueros y la biodiversidad de nuestras aguas. 
La actividad de la Pesca Marítima de Recreo está regulada por una serie de normas que regulan principalmente las clases, útiles y aparejos, periodos y zonas de veda, especies autorizadas y topes máximos de capturas.

\section{Red Española de mujeres en el sector pesquero}

El Ministerio de Medio Ambiente y Medio Rural y Marino, preocupado por fomentar la igualdad de oportunidades, ha promovido, a través de la Secretaría General del Mar, la creación de la Red Española de Mujeres en el Sector Pesquero, con la finalidad de hacer visible el importante trabajo que realizan en el mismo.

Una visibilidad que se conseguirá gracias a la participación de todos sus miembros en esta Red, que nace con la pretensión de convertirse en un canal interactivo en el que la interconexión e intercambio de experiencias sea una realidad, convirtiéndolo así en un auténtico medio de comunicación efectivo entre todas las personas vinculadas o interesadas en este sector.

A nivel internacional, la consecución de la igualdad de oportunidades en el sector pesquero también aparece secundada por la Comisión Europea quién, a través del Fondo Europeo de la Pesca, ofrece un marco de apoyo a la consolidación del papel de la mujer en el citado sector. Más allá de la reafirmación del principio de igualdad de género, el Reglamento FEP menciona explícitamente el acceso al mercado laboral para las mujeres y el trabajo en red de organizaciones que promueven la igualdad de oportunidades entre hombres y mujeres como áreas necesarias de apoyo.

Por todo ello, resulta importante recalcar la necesidad de promover y facilitar el acceso de las mujeres a asociaciones y redes, para que sirva de intercambio de experiencias y buenas prácticas, que pueden resultar muy interesantes para impulsar la actividad de la mujer en el desarrollo sostenible de la pesca.

La red se trata de una red nacional que persigue fomentar el trabajo en red, la comunicación e intercambios de experiencias entre las mujeres que trabajan, o desean trabajar en el sector pesquero en cualquiera de sus diversas actividades. Así como aportar visibilidad y refuerzo del papel de éstas y de las organizaciones dedicadas a promover la igualdad de oportunidades, a través de seminarios, programas de formación y de investigación.

La Red tiene como finalidad la interacción de sus miembros, fomentando la comunicación e intercambios de experiencias entre éstos, que a modo de buenas prácticas puedan servir para contribuir a que la igualdad de oportunidades sea una realidad en el sector de la pesca español.

\section{EL ÁMBITO LOCAL}

En cuanto al ámbito local, nos desplazamos al pueblo costero de Villajoyosa situado al sur de la Comarca de la Marina Baja, en la provincia de Alicante (Comunidad Valenciana, España). Se trata de un municipio que desde tiempos pasados una de sus principales sectores económicos es la pesca, por esa cercanía al mar Mediterráneo. 
Durante el siglo XX, se produjo el auge del sector pesquero en este municipio que junto con la creación del puerto en los años 20 y 30, se creó una gran flota pesquera que llegó a ser de las más importantes de la provincia de Alicante, donde muchas familias de este municipio se trasladaron a otras ciudades como Algeciras a obtener mayores beneficios. Se trataba de una flota cuya producción de pescado se destinaba para el consumo humano. La pesca no solamente da actividad a los empleados que se van con las barcas a faenar sino también a un consolidado número de población, la mayoría mujeres que se quedaban en tierra firme construyendo o arreglando las redes de los pescadores. Este municipio tiene la singularidad que las viviendas del casco histórico actual, cada una esta pintada de un color distinto debido a que los marineros cuando se iban a trabajar, estaban fuera de casa ciertos meses y cuando volvían reconocían sus viviendas gracias al color de estas.

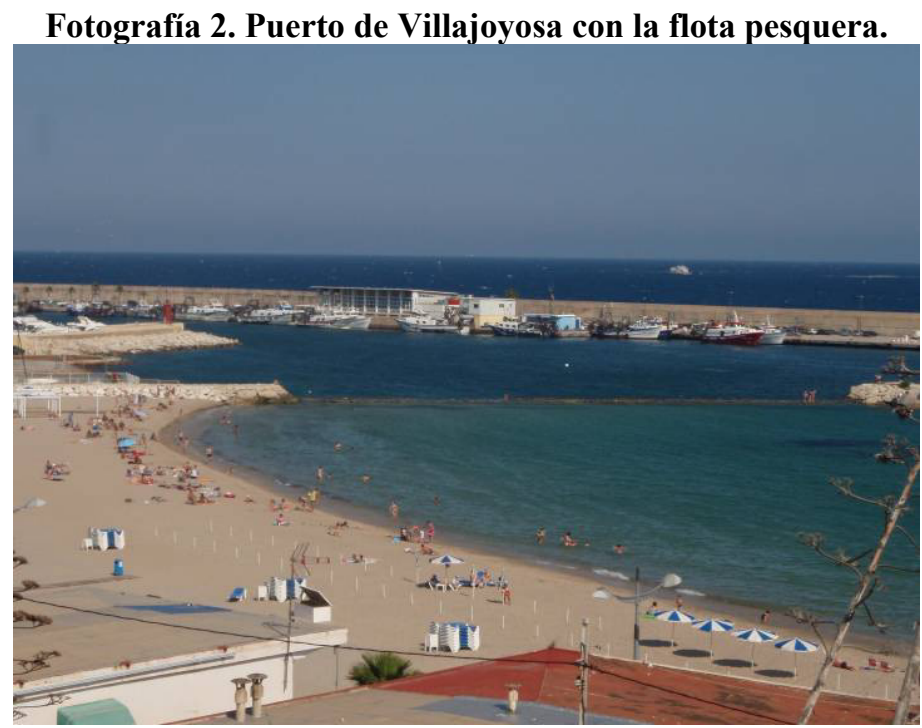

Autor: Gaspar Lloret (junio de 2011).

\section{Cofradía de Pescadores de Villajoyosa}

En la actualidad se ha creado la Cofradía de Pescadores de Villajoyosa es una entidad sin ánimo de lucro y de ámbito local. Actualmente está compuesta por trescientos veinticinco cofrades en activo entre tripulantes y propietarios de embarcaciones o armadores. Estas dos partes están representadas por igual en los diferentes órganos de gobierno de esta Entidad. Es decir, la Junta General formada por veintitrés representantes de armadores y el mismo número de representantes de los tripulantes; y la Junta de Cabildo constituida por cinco representantes de armadores y cinco representantes de tripulantes. Éstos son elegidos mediante votación por el total de lo cofrades. Y durante este proceso electoral son nombrados tanto el Presidente ó Patrón Mayor (representantes armadores) como el Vice-Patrón Mayor (representante tripulantes). Estas elecciones se celebran cada cuatro años con el fin de renovar los citados cargos. Cualquier decisión o asunto que ataña a este colectivo es tratado inicialmente por la Junta de Cabildo y se traslada posteriormente para su ratificación definitiva a la Junta General.

La función principal de esta Cofradía es la de representación de los intereses económicos y sociales de sus afiliados. Siendo principalmente la gestión de venta de las 
capturas realizadas por las cincuenta y tres embarcaciones afiliadas en la actualidad. Así mismo se ofrece a los cofrades una serie de servicios como son: suministro de hielo para la conservación de los productos pesqueros; suministro de combustible; asesoramiento en temas económicos (facturación: cobro y pago de las ventas) y laborales (expedientes de regulación de empleo, jubilaciones, partes de altas y bajas, contratos laborales, boletines de cotización).

Debido a la constante evolución de las normas y leyes que rigen al sector pesquero y al interés de la cofradía por estar informada para así favorecer al buen funcionamiento de la explotación pesquera sujeta a ella; estamos afiliados a las diferentes Federaciones de Cofradías tanto a nivel provincial como nacional. Contribuyendo económicamente a la financiación de las mismas.

El presidente o patrón mayor D. José Ignacio Llorca Ramis está poniendo en práctica una iniciativa desde la Cofradía de Pescadores de Villajoyosa que se trata de la instalación de un contenedor en cada una de las embarcaciones para almacenar todos aquellos elementos inorgánicos que son arrojados al mar por los grandes buques de mercancías o embarcaciones deportivas como pueden ser botellas, bolsas, latas, plásticos en si, etc., y almacenarlos en esos contenedores para llevarlos a los vertederos en tierra firme. Hasta ahora las embarcaciones cada vez que sueltan las redes recogen una gran cantidad de residuos que son nuevamente desechados al mar, pero con esta propuesta se puede conseguir una limpieza de los fondos marinos, mejorando las condiciones de hábitat de los medios marinos. Esta iniciativa está a la espera de ser aprobada por la Generalitat Valenciana.

Según el Presidente de la cofradía, la pesca ilegal, no declarada y no reglamentada también la observamos en estos municipios donde el total de la producción de peces, anteriormente el $70 \%$ de las especies que eran capturadas se vendían en la lonja, pero el resto, es decir el 30\% restante era en negro, ya que mediante las cofradías o por las propias embarcaciones vendían ese pescado a unas empresas donde estas le pagan directamente al patrón de las embarcaciones sin declarar. De este modo los marineros obtenían mayores beneficios, ya que la ganancia era directa. Desde la entrada en la Cofradía del presidente actual, todo esto ha terminado debido a diversos desfalcos que se han producido dentro de dicha institución por diversos empleados, sin poder hacer nada al respecto, ya que era dinero negro.

En cuanto a la flota pesquera se ha producido una reducción del número de embarcaciones a partir del año 2000, pero la caída más acentuada se produce entre 2004 - 2006 debido a la subida de los precios de los carburantes, ya que estamos hablando de embarcaciones que necesitan unos 1.000 litros de combustible al día lo que supone que el patrón de la embarcación tiene que pagar alrededor de $1.000 €$ cada día que sale a faenar solamente de combustible, sin apenas contar el sueldo de los trabajadores. Para salirle rentable el día deberían obtener unos $2.000 €$ de beneficios en la venta de las capturas del día para poder hacer frente a todos los gastos. Hoy por hoy el combustible de estas embarcaciones les cuesta a $0.65 €$ el litro gracias a las ayudas del Estado.

A todo esto se le une las medidas de la Política Pesquera Común con subvenciones y ayudas para desguazar los barcos para reducir la capacidad extractiva. En Villajoyosa en la actualidad, realizan actividades pesqueras 30 embarcaciones de arrastre que se 
realizan mediante una gran bolsa de red de altura variable, que por diversos medios se mantiene abierta y se arrastra por el fondo marino, el rendimiento pesquero de dicho arte irá consecuentemente ligado al tamaño y potencia del barco que arrastre dicha bolsa; a mayor potencia, mayor es el arte. Es una de las artes de pesca que ha tenido más aceptación, y donde el desarrollo industrial ha tenido una gran incidencia. En menos de un siglo ha experimentado cambios verdaderamente notables. Y 5 de artes menores también denominado trasmalla, que utilizan unas redes y aparejos distintos a las otras modalidades de pesca. En general se practica la pesca cerca de la costa, utilizando una red de malla que se cierra por debajo mediante un cabo. No obstante, y al tratarse de embarcaciones autónomas, la decisión sobre los utensilios empleados y las zonas de explotación es muy dispar. Las especies que se capturan mediante este arte son muy apreciadas. Entre ellas podemos destacar el salmonete, el langostino, el lenguado, la merluza y la lubina.

En estos municipios del litoral mediterráneo como pueden ser Gandia, Calpe, Altea, Campello, Santa Pola, etc., la gran mayoría de las embarcaciones pertenecen a familias que se han dedicado desde años atrás a esta actividad, no suelen ser empresas dedicadas a la captura pesquera. Otro dato característico es que al ser embarcaciones familiares, la mayor parte de los trabajadores son familiares, padres, hijos, hermanos y primos. Se trata de familias con un nivel de rentas bastante elevado, donde anteriormente aquellas familias que poseían una embarcación eran las que tenían cierto poder económico.

Como podemos observar en la figura 10 posterior, a medida que reducen el número de la flota pesquera se produce una disminución paralela de empleados de este sector. En cuanto al número de empleados, en el primer periodo 2003 - 2004 se produce un descenso continuo, pero en el siguiente 2004 - 2006 se produce una caída acentuada del número de empleados pasando en dos años de 250 trabajadores a 198. En los años 2006 - 2007 se produce un pequeño ascenso pero a partir del 2007 vuelve a haber una fuerte caída hasta 2009 que pasa de 203 trabajadores a 171. Desde el 2009 hasta la actualidad sigue descendiendo pero a unos niveles más leves, en que llega en la actualidad a 162 empleados en el sector pesquero.

Por lo que respecta a las embarcaciones, observamos un descenso prácticamente constante donde en escasos años $(2003$ - 2011) el número de embarcaciones pasa de 52 a 30, esto es ocasionado a que se trata de un sector en crisis donde los dueños de las barcas cada vez obtienen menos beneficios y se cree que irá a menos, y cuando tienen la oportunidad de desguazarlas para obtener unos incentivos no desaprovechan la oportunidad.

En cuanto a los caladeros, los más visitados por la flota pesquera de Villajoyosa son los de Sant Antonio, Formentera e Ibiza, y a partir de las 30 millas de la costa. Y las especies más frecuentes a lo largo del año son el jurel, merluza, pescadilla, gamba roja, pulpo, cigala, galerotes, etc. Dependiendo de la época del año se pueden capturar unas especies u otras, como la dorada que aparece en aquellos meses donde la temperatura del agua es más fría (invierno y primavera). También dependiendo de la profundidad encuentran una serie de especies:

- Entre los 50 y 100 metros: se encuentra el jurel, bacalao, pescadilla, morralla, etc.

- Entre los 100 y 250 metros: bacalao gordo, quisquilla, brótola, etc. 
- Entre 250 y 500 metros: cigala y la gamba roja.

Figura 10. Número de embarcaciones y tripulantes en el periodo 2003 - 2011.

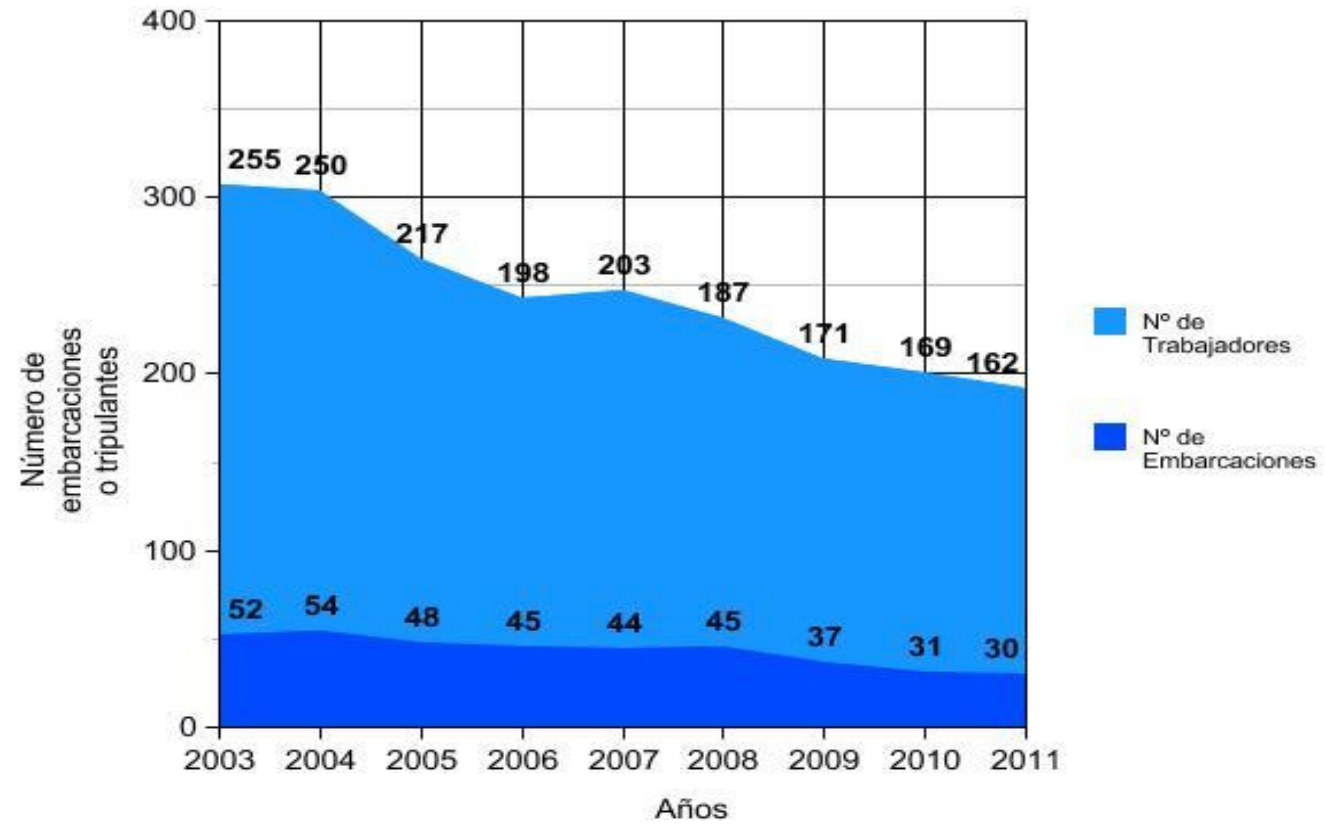

Fuente: Cofradía de Pescadores de Villajoyosa. Elaboración propia.

En el litoral Mediterráneo donde no se han establecido Zonas Económicas Exclusivas, el grado de explotación de mediados de los noventa era muy superior al de mediados de los ochenta. Para hacer frente a esta sobreexplotación, en el caladero mediterráneo se aplica desde 1995 un Régimen Común de Conservación de la Pesca, basado en el establecimiento de paros biológicos. Según el presidente de la Cofradía, José Ignacio Llorca el paro biológico viene recomendado por los biólogos, dependiendo de los años suele cambiar ya que unos años lo hacen en unos meses determinados y en otros años cambia. Casi siempre se ha producido en el mes de mayo, que era cuando los peces ya habían dejado los huevos y los peces tenían un tamaño pequeño. Pero por ejemplo, en este año 2011 se ha producido desde el 15 de enero al 15 de febrero para evitar la captura a las madres huevando y también se está planteando parar el mes de septiembre pero según el presidente de la cofradía este mes se trata de un paro más que nada para evitar el coste de los combustibles, y no por la propia renovación de las especies.

Según el presidente de la Cofradía se prevé un futuro incierto en la pesca en este municipio y en el resto de municipios que se dedican a una pesca bajura como sucede en Villajoyosa, bien por el precio de los carburantes o bien por las continuas leyes que se aprueban desde la Política Pesquera Común en la que cada vez se exigen mayores medidas de seguridad como son unos chalecos salvavidas especiales con unos precios desorbitados en que cada uno de estos cuesta 3.000€, instrumentos para tener controlados a las embarcaciones, medidas para avisar a que caladero van a ir, el número de capturas que se produce en que anteriormente se ponían en papel y bolígrafo, y en la actualidad se exige en ordenador y todos los días, y todo eso unido al aumento de las 
inspecciones por parte de la guardia civil en que cada día van a controlar las capturas, el tamaño de las redes, etc. Se les exige unas condiciones a las flotas de bajura como si fueran de gran flota.

En la lonja de Villajoyosa, habitualmente se realiza la subasta de pescado todos los días y capta la expectación de los visitantes que acuden esperando ver algo parecido a lo que sucede en las subastas de otros productos.

El lugar de la lonja de pescado es como un anfiteatro bastante inclinado, desde los asientos se observa el pescado fresco recién desembarcado de las embarcaciones pesqueras, bien presentado y acomodado en cajas de plástico. Estas cajas circulan por una cinta transportadora y la puja se realiza al instante y de un modo veloz. La tecnología juega un papel fundamental en las subastas que se realizan en esta lonja, en un extremo se encuentra un operario que se encarga de introducir en el sistema informático los datos de cada caja, es decir, el tipo de pescado y el precio de salida, en el otro extremo otro operario se encarga de dar el visto bueno a cada venta adjudicada y dar paso a la caja o cajas de pescado adquiridas.

\section{Funcionamiento de la lonja de pescado}

En el centro se encuentra un gran tablero electrónico que proporciona la información sobre el pescado, el barco pesquero que lo ha traído, el tipo de pescado, la cantidad de cajas del lote, el peso total y el precio de salida por kilo. Cada asiento del anfiteatro cuenta con un dispositivo electrónico en el que se introducen los datos de quien quiere comprar pescado y con él se realiza la compra de pulpos, langostinos, lenguados, sepias, merluzas, etc.

La subasta no es cómo podríamos pensar (el que ofrece mayor precio se adjudica la mercancía), en realidad se ofrece un precio inicial de salida y poco a poco se va reduciendo, el primero que pulsa el dispositivo se queda con la mercancía. Suponemos que los patrones de los pesqueros tendrán en cuenta esta peculiaridad y saldrán con precios elevados, también existen medidas para evitar que los compradores se pongan de acuerdo y dejen reducir el precio bajo mínimos, de hecho hay un tope. Las cajas se pasean por la cinta a velocidad de vértigo y por cada compra realizada se emite, a través de una impresora, la etiqueta identificativa que muestra quién ha realizado la compra. 


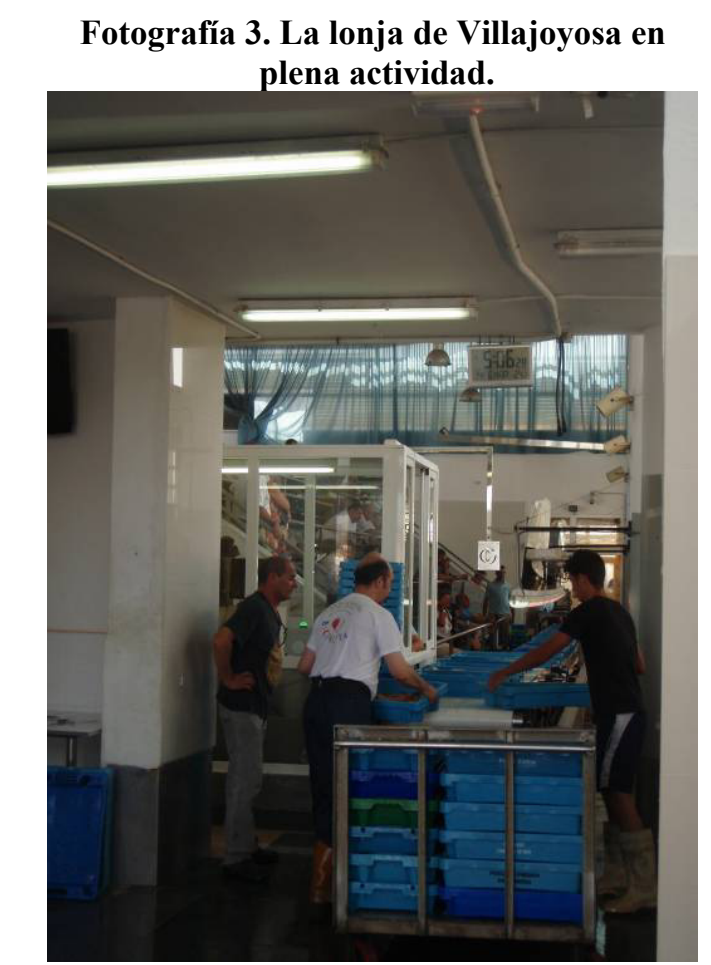

Autor: Gaspar Lloret (junio de 2011).

\section{ACUICULTURA}

La acuicultura es el cultivo de organismos acuáticos incluido peces, moluscos, crustáceos y plantas acuáticas. El cultivo implica algún tiempo de intervención en el proceso de cría para aumentar la producción, como por ejemplo la estabulación de individuos, la alimentación, la protección frente a depredadores, etc.

La acuicultura se produce desde hace 4.000 años, pero sólo durante los últimos 50 años se ha convertido en una actividad socioeconómica de importancia generando 9,8 millones de puestos de trabajo en todo el mundo (FAO 2004). Su contribución al suministro mundial de peces, crustáceos y moluscos aumenta año tras año. Según la FAO, la contribución de la acuicultura al suministro mundial de productos pesqueros (en peso) ha pasado del 3,9\% en 1970, al $29,9 \%$ en 2002 y con previsión de alcanzar el $50 \%$ en 2025. Además se debe resaltar que ya en 2006 casi la mitad de los productos pesqueros destinados al consumo humano directo provienen de la acuicultura.

El sector acuícola tiene un crecimiento más rápido que cualquier otro sector de productos alimenticios de origen animal. A escala mundial, este sector ha crecido una media del 8,9\% anual desde 1970, mientras que otros ecosistemas de producción cárnicos terrestres lo hicieron en un 2,8\%.

Más del 90\% de la producción acuícola de Asia (principalmente China), un 3,5\% de Europa Occidental, un 0,4\% de Centro Europa y Europa del Este, un 2,3\% de Latino América y el Caribe, un $1,3 \%$ de Norte América y un $0,9 \%$ de Oriente Medio y África del Norte, con el 0,2\% restante proveniente del África sub-Sahariana.

La acuicultura es una actividad que incluye multitud de prácticas diversas y un amplio abanico de especies producidas, sistemas y técnicas. Su dimensión económica ofrece 
nuevas oportunidades socioeconómicas en las regiones donde se establece, gracias a la creación de puestos de trabajo, el uso cada vez más eficiente de los recursos naturales y a la promoción del comercio local e internacional. El éxito de la acuicultura moderna se basa en el control de la reproducción de especies, un mejor conocimiento de la biología, innovaciones tecnológicas y el desarrollo de productos alimenticios seguros y de alta calidad.

La mitad de la producción mundial de acuicultura en 2003 provino de la producción de peces, pero el incremento en la producción se refiere a todos los grupos de especies.

Las principales especies cultivadas a nivel mundial son peces omnívoros y herbívoros. Estas especies se producen principalmente en países desarrollados, con un producción siete veces mayor que la de los peces carnívoros, que se cultivan principalmente en los países desarrollados.

En comparación con la explotación de los sistemas agropecuarios terrestres, donde la mayoría de la producción se obtiene a partir de un reducido número de animales y plantas, durante el 2003 se cultivaban más de 210 especies animales y vegetales en el mundo. Esta diversidad es debida al elevado número de organismos acuáticos que se pueden adaptar a sistemas y condiciones de producción controlados.

Figura 11. Producción mundial de acuicultura por volumen en 2004 por regiones.

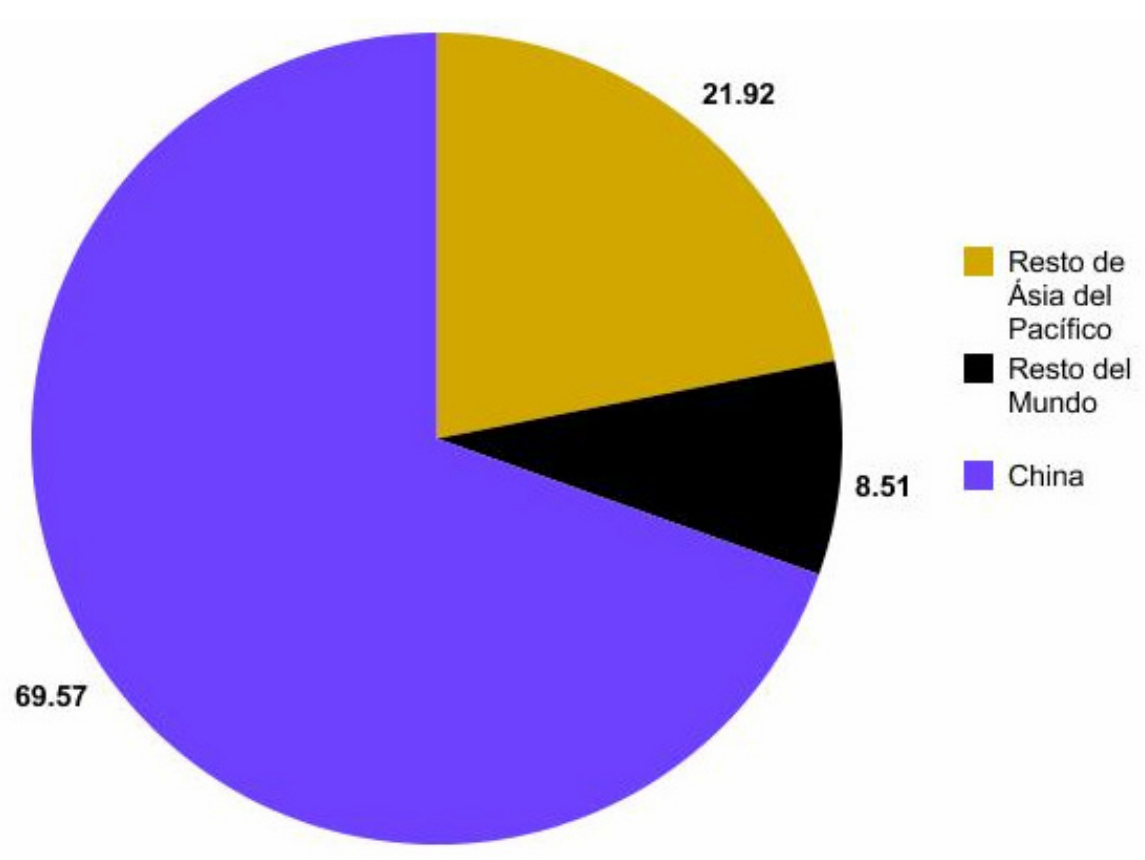

Fuente: FAO, 2006. Elaboración propia.

Durante los últimos treinta años, la acuicultura ha crecido, se ha diversificado y ha registrado enormes mejoras tecnológicas. El potencial de estas mejoras para el bienestar socioeconómico - tanto en países desarrollados como en desarrollo - para la mejora de la calidad de vida y para el aumento de la seguridad alimentaria, ha sido reconocido por la FAO en su Declaración y Estrategia de Bangkok (2000). En dicho documento se 
resalta la necesidad de respaldar el desarrollo potencial de la acuicultura en beneficio de los seres humanos.

En la región mediterránea, la acuicultura se ha expandido rápidamente durante las últimas dos décadas, con una tasa de crecimiento anual que pasó de un $4 \%$ en 1980 hasta un $13 \%$ en el 2000 , y con una tendencia hacia la diversificación de especies cultivadas que facilita el crecimiento del sector.

Aunque la producción acuícola mediterránea se basó principalmente en el cultivo de moluscos durante los años 90, la proporción del cultivo de peces sigue aumentado hoy en día. Comparando la producción de la acuicultura Mediterránea desde 1994 a 2003, se observó un incremento significativo en la producción de peces (casi tres veces mayor); al mismo tiempo se produjo un aumento de la producción de moluscos.

A los organismos cultivos se les tiene que proporcionar alimento para aumentar su productividad. Algunas especies filtradoras, como los mejillones, almejas u ostras, obtienen el alimento directamente de la columna de agua que nos rodea. Pero en la mayoría de casos (todos los peces y crustáceos) es el acuicultor quien debe proporcionar el alimento.

Figura 12. Producción mundial de acuicultura por volumen en 2004, sin contar Asia.

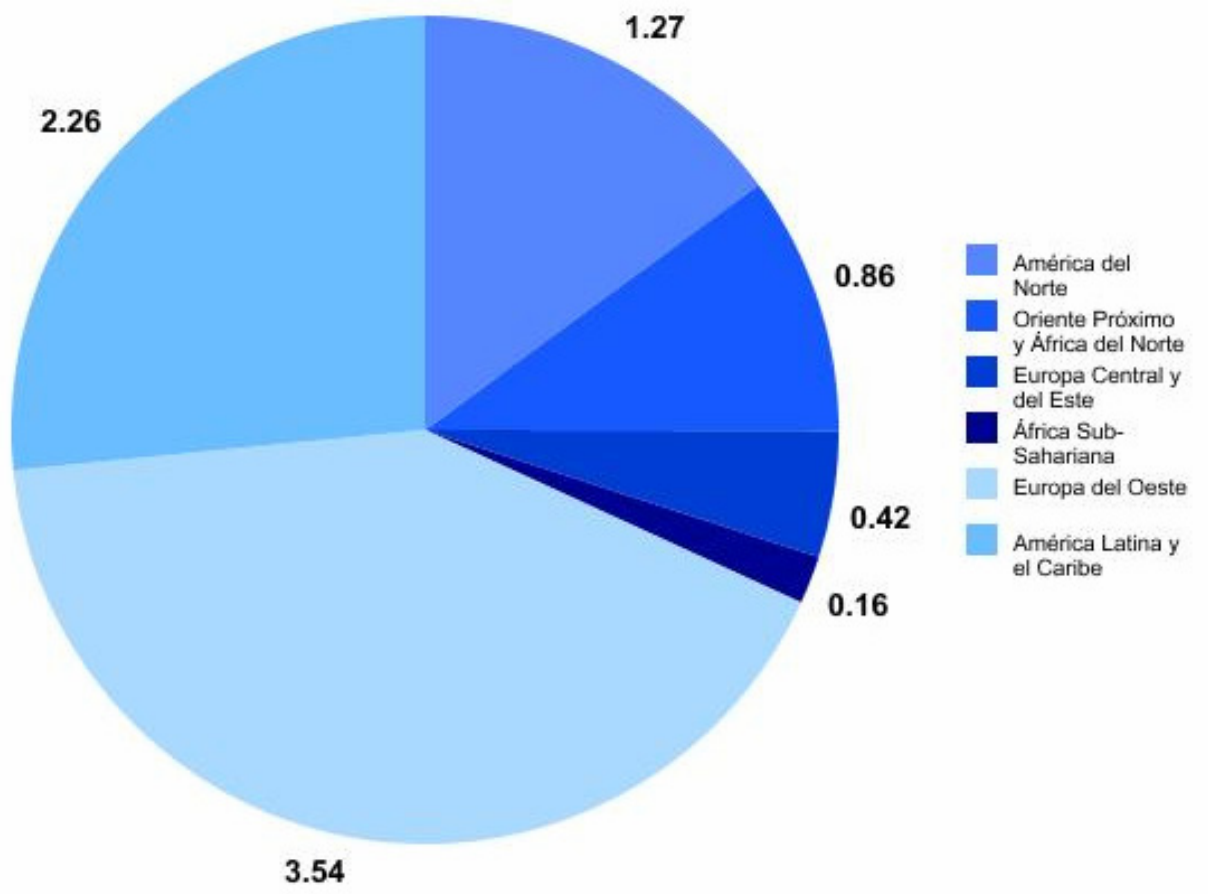

Fuente: FAO, 2006. Elaboración propia.

El alimento es el mayor aporte externo hacia el sistema de cultivo, y la cantidad de alimento requerido es, en general, dos o tres veces el volumen de producto final que se 
produce. Para la fabricación de estas dietas, se requieren grandes volúmenes de materias primas.

Las principales especies cultivadas en la región Mediterránea son la dorada, lubina, y lisa. Aunque la lista es una especie herbívora / omnívora, tanto la dorada como la lubina son animales carnívoros que se alimentan de otros peces, moluscos, crustáceos y gusanos en la naturaleza. Debido a ello, históricamente los principales ingredientes de las dietas para peces cultivados han sido la harina y aceite de pescado, obtenido de peces silvestres de todo el mundo. La harina y el aceite de pescado son materias primas cuya comercialización ha estado sujeta a la globalización. Son producidas por flotas pesqueras y plantas de procesado que se dedican específicamente a esta tarea. Los peces silvestres capturados para este fin son generalmente de pequeño tamaño y con gran cantidad de estructuras óseas, por lo que su demanda es reducida o nula para el consumo humano directo.

La fauna y flora locales pueden verse afectadas por las actividades acuícolas, pero esta interacción no siempre es negativa; puede ser incluso positiva. Los efectos pueden ser producidos como resultado del proceso de alimentación, excreciones de los organismos, efluentes y escapes. Muchas de las preocupaciones sociales derivan de los efectos medioambientales observados de la producción en los viveros marinos de cultivo o en los sistemas basados en tierra sobre la fauna y flora locales.

\section{Ecoturismo en granjas acuícolas}

Así como las granjas áreas rurales, las instalaciones acuícolas se pueden transformar en atracciones turísticas. Aparte de visitar las instalaciones y observar los sistemas de producción, los turistas pueden aprender acerca de la integración de la producción acuícola en el medio ambiente. El hecho de que un gran número de peces y otros animales pueden ser atraídos por los viveros marinos puede utilizarse como reclamo turístico, ofreciendo por ejemplo inmersiones subacuáticas alrededor de los viveros. Por lo tanto, los turistas tendrían una mejor imagen de la acuicultura, y los productores se verían incentivados a mantener granjas acuícolas y sus alrededores limpios para transmitir una imagen positiva de su actividad. Además, el producto se podría vender directamente a los turistas.

\section{La acuicultura en España}

Hasta la década de los ochenta la producción acuícola española se concentraba en unas pocas especies repartidas en pequeñas empresas de economías familiares y muy tradicionales, siendo tres los cultivos más característicos:

- Cultivo de mejillón en las rías gallegas. Iniciado en los años cuarenta, su desarrollo se produjo a mediados de los setenta.

- Cultivo de la trucha arco iris, su desarrollo tuvo lugar en los años setenta.

- Acuicultura de los esteros gaditanos, iniciada a comienzos de los cuarenta al entrar la industria salinera local en una grave crisis, su desarrollo fue muy lento en un principio, logrando su despegue definitivo a finales de los años setenta. 
En España, a partir de los años noventa, con la incorporación de nuevas tecnologías y una mayor industrialización del sector, se incorporaron nuevas especies como el rodaballo en el norte de España y la dorada y lubina en el sur y levante de España y Canarias. Además, el cultivo del mejillón incrementó su grado de industrialización y se mejoraron los métodos empresariales en los cultivos de trucha y en los esteros de la región sur atlántica.

La actividad acuícola en España se sustenta en torno a 3.400 empresas, según los datos de la Subdirección General de Estadística del MARM del año 2007. De éstos, el 95\% se ubican en zonas marinas y el resto en aguas continentales. Según los últimos datos aportados por las Comunidades Autónomas a JACUMAR, la producción española de acuicultura continental y marina, alcanzó, en el año 2008, 265.313,13 Tm., correspondiendo $65.262,51 \mathrm{Tm}$. a peces, $199.923,86 \mathrm{Tm}$. a moluscos y $113,09 \mathrm{Tm}$. a crustáceos.

En general, se puede decir que la mayor producción acuícola española corresponde a moluscos, especialmente mejillón con un $72,69 \%$ del total. La producción de peces, tanto de acuicultura marina, como continental, supone un $24,59 \%$ del total, especialmente dorada, lubina, rodaballo, túnidos y trucha y, aunque este porcentaje es bajo, la producción de peces marinos ha experimentado un espectacular crecimiento multiplicándose casi por dos en los 6 últimos años.

\section{Los Planes Nacionales}

Hace unos años se crearon los Planes Nacionales por la ley de Cultivos Marinos, en cuyo artículo se estableció que el Ministerio de Agricultura, Pesca y Alimentación podría proponer a las Comunidades Autónomas este tipo de iniciativas. Según la Ley se elaborarían conjuntamente entre el Ministerio y las Comunidades Autónomas y serían ejecutados por estas últimas en el ámbito de sus competencias estatutarias. El seguimiento de los planes lo realizaría la Junta Nacional Asesora de Cultivos Marinos.

Un Plan Nacional es una acción destinada al fomento y desarrollo de la acuicultura marina de forma armónica en el territorio nacional. Se orientan al logro de objetivos específicos suficientemente concretos como para eliminar generalidades $\mathrm{y}$ ambigüedades y que sean de interés para una parte significativa de nuestro país.

Los objetivos pueden ser tanto de investigación, desarrollo e innovación como de cualquier otra actividad relacionada con la acuicultura cuya consecución se considere importante para el desarrollo armónico de la actividad acuícola.

Los Planes se identifican y se aprueban en JACUMAR. Por regla general, son propuestos por Comunidades Autónomas aunque no se excluye la posibilidad de su propuesta por otra parte interesada. La puesta en marcha de un Plan está condicionada a la existencia de un interés común a varias Comunidades Autónomas considerándose como criterio de selección prioritario la participación de, al menos, tres Comunidades Autónomas.

Una vez aprobado un Plan, se constituye un grupo de trabajo que identifica el desarrollo que debe tener el mismo. Posteriormente, se identifican y proponen los equipos que 
pueden abordar cada una de las tareas. Estos grupos pueden ser tanto de investigación como de otra actividad y pertenecen a la Universidad, Institutos de Investigación o empresas privadas. Las tareas concretas se reparten entre las Comunidades Autónomas a quienes les cabe la responsabilidad de la gestión económica de los Planes. Existe un Grupo de Seguimiento que se encarga de evaluar sus resultados de los Planes mediante el análisis de los informes anuales de ejecución y los informes finales. Este grupo está constituido por un representante de cada Comunidad Autónoma y por personal de la Secretaría de Jacumar.

\section{Fundación Observatorio Español de Acuicultura (FOESA)}

La recientemente constituida Fundación Observatorio Español de Acuicultura, nace con objetivos renovados y amplitud de miras, contando con un mayor respaldo al estar representadas en su patronato algunas de las principales instituciones cuyo ámbito de actuación es la investigación, el desarrollo tecnológico o la innovación, como el Instituto Español de Oceanografía, el Consejo Superior de Investigaciones Científicas, la Fundación Española de Ciencia y Tecnología y la Fundación Alonso Martín Escudero. Forman también parte del patronato la Dirección General de Ordenación Pesquera y la Junta Nacional Asesora de Cultivos Marinos (JACUMAR). En un futuro próximo será necesario y de gran interés para el correcto desarrollo de la Fundación, el poder contar con el apoyo de todas aquellas instituciones, asociaciones y empresas del sector acuícola español interesadas en participar y colaborar en la generación de propuestas y desarrollo de nuevas iniciativas.

El principal objetivo y fin de la fundación es de carácter de investigación en el campo de la acuicultura, persiguiendo los siguientes objetivos específicos:

- Servir de plataforma para el análisis y seguimiento permanente del desarrollo de la acuicultura en España, tanto en lo que se refiere a las actividades de Investigación, Desarrollo Tecnológico e Innovación $(\mathrm{I}+\mathrm{D}+\mathrm{I})$, como a las realizadas por las distintas administraciones públicas y por las empresas.

- Servir de plataforma de encuentro, análisis y debate interdisciplinar e intersectorial en la que participen las comunidades científicas, tecnológicas e industriales del sector de la acuicultura de España.

- Impulsar la presencia internacional de estos sectores en la perspectiva de un espacio europeo e iberoamericano.

- Impulsar la imagen de la acuicultura, promover la realización de proyectos de investigación, divulgar las investigaciones, la calidad de los productos de la acuicultura y acercar este sector a los diferentes colectivos sociales.

\section{CONCLUSIÓN}

Quizás sea demasiado pronto para establecer juicios de valor definitivos sobre el futuro de la pesca, pero la enseñanza que proporcionan los procesos históricos conocidos y la evolución actual de los acontecimientos políticos, económicos y sociales impiden el ejercicio de un abierto optimismo, tanto por lo que respecta a la propia supervivencia del sector como por lo que atañe a la consecución de un desarrollo sostenible, una 
equidad social sin fisuras y un bienestar duradera para la población destinada en esta actividad para la mayoría de los países que lo conforman.

El origen del modo de producción capitalista y los mecanismos del actual proceso de mundialización son los factores de la crisis del sector pesquero. A partir de la introducción de mejoras en la mecanización de las embarcaciones es cuando empezaron los problemas de sobreexplotación donde la producción llegó a multiplicarse por cuatro, sobre todo a partir de los años 80 . A partir de ese momento la producción fue creciendo hasta nuestros días en los que observamos una gran diversidad de problemas, bien de sobreexplotación de caladeros, destrucción de los fondos marinos, entre otros más. Las diversas instituciones internacionales, nacionales y locales intentan reducir estos impactos pero sin mayores beneficios, donde lo único que consiguen es estrangular aún más a los propietarios de las embarcaciones con mayores exigencias de instrumentos para localizarlos, chalecos salvavidas, controles por dimensión de las capturas, etc.

Desde hace años una de las medidas que se han tomado ha sido la reducción de las flotas pesqueras, estas medidas lo único que hacen es ocasionar problemas a la población que desde años se ha dedicado a ese oficio. Con el desguace de las embarcaciones los empleados reciben una subvención durante un año para que no trabajen en el sector, es decir, que no salgan al mar. Una vez pasado ese año ya podrían volverlo a hacer. Pero no todos esos empleados más tarde no pueden volver a trabajar en este sector ya que no habría suficiente embarcaciones para estas personas. Es decir, sería un aumento de la población desempleada, sin formación en ninguna actividad, ya que desde jóvenes se han dedicado al sector pesquero.

Otro de los problemas que se deberían de solucionar serían los desequilibrios de los precios al igual que sucede en los productos agrarios y ganaderos, en la que los productores producen o extraen esos elementos que luego más tarde las grandes empresas o cooperaciones compran esos productos a un escaso precio que no llega a alcanzar los costes de su producción. Si nos acercamos a la lonja de pescado, a lo mejor un $\mathrm{Kg}$. de atún nos saldría a $10 € / \mathrm{Kg}$. pero después el mismo atún nos desplazamos a la pescadería del municipio y su valor se ha triplicado. A mi modo de ver, este sería el gran problema de los pescadores, ese desequilibrio de precios entre el precio de producción y el precio en que más tarde se le vende al consumidor. Una buena solución, sería la construcción o formación de pescaderías de las mismas embarcaciones, así los beneficios serían para los propios pescadores, y no para los transportistas o grandes empresas.

Estas instituciones su labor va dirigida hacia una pesca sostenible, para poder hacer un equilibrio entre las necesidades de los pescadores y el mantenimiento de los caladeros, en la que se producen medidas como los paros biológicos para dejar de capturar las especies en su proceso de cría, y también se está produciendo un fuerte crecimiento en las instalaciones acuícolas que se están asentando como una solución a la sobreexplotación de los caladeros y a la reducción de las capturas. En fin, si los marineros y las instituciones quieren salvar los problemas y la crisis del sector pesquero deberán moverse todos ellos en la misma dirección, trabajando juntos para conseguir la sostenibilidad de la actividad pesquera llegando al equilibrio entre las extracciones y la supervivencia de los caladeros, sin destruir el entorno marino. 


\section{BIBLIOGRAFÍA}

BAS PERIED, C. El Mar Mediterráneo: recursos vivos y explotación. Barcelona: Ariel, 2002.

BURGESS G. H. O., GUTTIN C. L., LOVERN J.A. y WATERMAN J. J. El Pescado y las industrias derivadas de la pesca. Zaragoza: Acribia, 1987.

CERVERA PERY, J. El derecho del mar. Evolución, contenidos, perspectivas (de la Bulas Papales al Convenio de Jamaica), Madrid: Naval, 1992.

COLL MORALES, J. Acuicultura Marina Animal. Madrid: Mundi Presa, 1991.

Comisión Europea. La Política Pesquera Común. Guía del usuario. Luxemburgo:

Oficina de Publicaciones Oficiales de las Comunidades Europeas, 2009.

Comisión Europea. La Política Pesquera Común en cifras. Información estadística básica. Luxemburgo: Oficina de Publicaciones de la Unión Europea, 2010.

HERNANDEZ, J. A. y MANZANO, J. C. Avances en la Investigación pesquera y acuícola en el Ambito del Estrecho de Gibraltar. Cádiz: Universidad de Cádiz, 2006.

LACLETA, J. M. Las aguas españolas en la costa africana. Revista Electrónica de Estudios Internacionales, 2003.

RAMÓN RUBIR R. La Piscifactoría. Cría Industrial de los peces de agua dulce. México DF: C.E.C.S.A., 1978.

UICN. Interacciones entre la Acuicultura y el Medio Ambiente. Guía para el desarrollo Sostenible de la Acuicultura Mediterránea. Gland, 2007.

VÁZQUEZ GÓMEZ, E. M. Las Organizaciones Internacionales en Ordenación pesquera. La cooperación para la conservación y Gestión de los Recursos Vivos del Alto Mar. Sevilla: Consejería de Agricultura y Pesca, 2002.

\section{RECURSOS ELECTRÓNICOS}

Ministerio de Agricultura, Ganadería y Pesca.

$<$ http://www.marm.es/es/pesca/temas/default.aspx $>$

Las cuencas marinas.

$<\underline{\text { http://ec.europa.eu/maritimeaffairs/atlas/seabasins/index_es.htm }>}$

El Fondo de Regulación y Organización de Mercado de los Productos de la Pesca y Cultivos Marinos (FROM)

$<\underline{\text { http://www.from.es/es/from/presentacion/presentacion.aspx }>}$

Lonja de pescado. <http://www.gastronomiaycia.com/2008/09/24/lonja-de-pescado/> 
Tipos de pesca.

$<\underline{\text { http://www.tinet.cat/mediterranea/html/castella/pesca/tipus/arrastre/arrastre.htm }>}$

Cofradía de Pescadores de Villajoyosa. $<$ http://www.ctv.es/USERS/cofvila/> 